\title{
Games of policy and practice: multi-level dynamics and the role of universities in knowledge transfer processes
}

\author{
Irene Sala ${ }^{1}$ D $\cdot$ Maurizio Sobrero $^{1} \mathbb{D}$
}

Published online: 26 May 2020

(c) The Author(s) 2020

\begin{abstract}
This paper adopts a multilevel, longitudinal case study approach to analyze universities' institutional role and their contributions to society. It explores third mission policies and practices enacted within the University of Bologna from 1996 to 2016, presenting a detailed account of their interaction within the university and with regional and national regulatory initiatives. The aim is to highlight the relevance of a joint analysis of three dynamics. The first dynamic relates to how norms and practices oscillate between formal and informal codification and how strategic initiatives, either led from the top down or driven from the bottom up, develop in a non-linear fashion. The second dynamic describes the ways within which the structural definition of roles falls short in providing a full understanding of the changes in policies and attitudes related to knowledge transfer activities and their need to be complemented by a process analysis of the relationships among actors at different levels. The third dynamic relates to how multiple institutional logics evolve and change over time through a combination of dedicated structures and spaces of interaction in which the logics meet, sometimes aligning, sometimes compromising, and sometimes clashing. This three-pronged approach offers a novel contribution to the understanding of how universities interact with close and distant environments and their impacts on society.
\end{abstract}

Keywords Knowledge transfer · Universities · Local dynamics · Innovation policy · Institutional logics

JEL Classification $\mathrm{M} 13 \cdot \mathrm{O} 33 \cdot \mathrm{O} 34 \cdot \mathrm{O} 38$

\section{Introduction}

Studies have analyzed the role of universities and their contributions to society according to three main dimensions. The first dimension relates to their span of activities; this has been examined by several disciplines that have paid increasing attention to universities'

Maurizio Sobrero

maurizio.sobrero@unibo.it

Irene Sala

irene.sala3@unibo.it

1 Department of Management, University of Bologna, Via Capo di Lucca 34, 40126 Bologna, Italy 
third mission activities that encompass various forms of knowledge and technology transfer (KTT). The second dimension relates to the geographical influence of universities and the consequences of that influence on local and global policies. The third dimension focuses on universities as institutions that are experiencing changes in their values, actions, and logic.

The relevance of university support for knowledge-based economic development through KTT is significant and consistent. Following a comprehensive review by Foray and Lissoni (2010), scholars (e.g., Kenney and Mowery 2014; Valero and Van Reenen 2019) have used a variety of methodologies to focus on single institutions (e.g., Nelson 2012), specific organizational units_-such as technology transfer offices (TTOs) (e.g., Tseng and Raudensky 2014), and individual actors (e.g., Sauermann and Stephan 2013). While studies mainly focus on U.S. cases and data, scholars are beginning to explore other contexts and highlight the role of institutional differences to assess general regularities and local specificities (e.g., Breznitz and Etzkowitz 2016). So far, however, research on formal KTT mechanisms focused primarily on university patenting and university-linked start-ups, not fully considering the multiple ways - direct/indirect, formal/informal—that universities affect society (e.g., Link et al. 2007; Nelson 2012). We need to better understand of KTT mechanisms (e.g., student internships, staff mobility, faculty-company consulting), the role that universities play as political institutions, and how universities shape internal and external contexts.

Spatial analysis of the impact of universities has evolved along with universities' relationships to various models of innovation (Feldman 1999). The linear view, in which publicly funded institutions produce basic science and transfer it directly to companies for commercial exploitation, or transform, adapt, or promote it through various intermediaries, is the classic model of spatial economic analysis. According to this view, universities are critical components of local economic systems and regional policies; they promote and sustain clusters and spatial aggregation (Anselin et al. 1997). However, national innovation system literature has questioned whether the linear model accurately represents the different phases, sequencing, and interactions of the innovation process (Nelson 1993). National innovation system literature has focused on a higher level of analysis that defines complete institutional settings as those with analogous functions and roles in the innovation process and allows for variations in actors and institutions according to local specificities. Growing acknowledgment of the many fallacies of the linear model has contributed to the development of more interactive, dynamic perspectives. These perspectives consider multiple roles and actors simultaneously and focus on their interactions-rather than their functions - to model their contributions to policy and society (Etzkowitz and Leydesdorff 2000; Leydesdorff and Etzkowitz 1996). Accordingly, the role of universities as political institutions becomes more relevant to gaining a full understanding of the evolution of local and national innovation systems.

Both perspectives implicitly characterize universities as being deeply rooted in Merton's (1973) original description of academic logic, involving peer recognition, the quest for individual professional freedom, and the adoption of an open attitude to knowledge dissemination. In contrast, the world of corporate $R \& D$ focuses on exploitation and appropriation, rather than exploration and sharing, and relies on higher salaries to attract researchers and compensate them for their limited freedom and higher bureaucratic control (Aghion et al. 2008; Dasgupta and David 1994). Institutional logic approaches analyze these opposing characterizations to question their separation (Thornton and Ocasio 2008; Thornton et al. 2012). Their goal is to analyze the relevance of their coexistence to fully understand the internal and external dynamics of technology transfer processes. Institutional logics 
are generally represented as Weberian ideal types. Although they are difficult to observe directly, they offer anchoring models to compare different organizational forms, managerial processes, and collective and individual decisions (Perkmann et al. 2019; Sauermann and Stephan 2013). Various scholars have relied on this perspective to model intermediaries in technology transfer as boundary-spanner solutions that reconcile differing institutional logics (Villani et al. 2017), analyze the role of different institutional features (Sauermann and Stephan 2013; Wadhwani et al. 2017), and document the definition and resilience of organizational culture and norms (Feldman and Desrochers 2003).

Although the literature has implicitly assumed the interactions between these three perspectives, it has rarely fully explored them, even though they offer opportunities to extend our knowledge of the development of local ecosystems and knowledge transfer practices and policies. In this paper, we combine the three perspectives mentioned above to analyze the role of universities as political institutions and determine how they contribute to local economic development. To do so, we focus on three related aspects.

First, as several comparative analyses show, the relationship between regional policies and universities' choices is complex and highly path-dependent (e.g., Kenney and Mowery 2014; Roberts 2018). Sub-national, national, and supra-national policies, the evolution of different institutional logics, economic cycles, and local dynamics affect relationships between universities and their local environments in different ways. Accordingly, to develop a clearer understanding of the dynamics linked to KTT, it is crucial to account for these multiple processes and determine their mutual influence and impact.

Second, many regions want to become the next Silicon Valley. However, there is clear evidence of repetitive failure (Lerner 2009; Brown 2016). A less ambitious, gradual improvement of local ecosystems, built on existing strengths to exploit distinctive advantages, seems more effective. Although universities can play a primary role, they are pulled in opposing directions: strengthening their local environments and operating in the international arena to attract more significant funding and find the best students, faculty, and staff. Lack of coordination between universities' objectives and national and local policies may generate systemic inconsistencies that affect universities' choices and limit their territorial impacts.

Third, actors and environment-specific characteristics matter (Autio et al. 2014; Guiso et al. 2004). Universities' abilities to produce positive local impacts are linked closely to how they intertwine and interact with local companies, clusters, and networks (Audretsch et al. 2019). This intertwining implies a focus not only on resource endowments, but also on the extent to which institutional logics, reputation, and expected influence shape opportunities to build and maintain local relationships (Thornton et al. 2012). In particular, we draw attention to universities' leaders, their abilities to form reference groups, and the targets of their strategic actions.

To address these various elements, we employ a historical case study of the evolution of KTT policies and practices at the University of Bologna from 1996 to 2016. We examine the interactions of these policies with regional and national regulations, and the simultaneous evolution of research practices, leveraging four institution-specific characteristics. First, given its history and reputation, the University of Bologna is a key actor within the national university community; its choices shape both formal and informal norms and practices (Baldini et al. 2014). Second, through various leadership practices and forms of governance, the University has played an essential role in the country's evolution of knowledge transfer practices and has dedicated resources and organizational attention to strengthening and adapting its research and teaching efforts. Third, the University's multiple branches span half the territory of Emilia-Romagna, one of Europe's most innovative regions, which 
in the time frame of our study developed a set of policies in support of university-industry collaborations (Bianchi and Labory 2011). Fourth, although the University of Bologna, like other Italian universities, is far from ranking among the world's top universities. However, in recent years it has consistently scored in the top three of all international and EU rankings in terms of student mobility, competitive funding, and research productivity (e.g., Times Higher Education 2019). These four characteristics allow us to incorporate into our analyses all significant elements included in the previously mentioned theoretical perspectives.

We offer three distinct contributions to the theoretical debate on universities as political institutions, conceptually linking technology transfer, regional policies, and the institutional logics perspective. First, we analyze whether and how top-down policies and bottom-up initiatives develop in a non-linear fashion and challenge the normative assumption of knowledge transfer models. Second, we analyze whether and how the structural definition of roles falls short in accounting for changes in policies and attitudes toward knowledge transfer activities. We call for process-based analyses that complement the dominant focus on outputs and results. Third, we analyze whether and how multiple institutional logics evolve and change over time. We, therefore, add a longitudinal component to the understanding of the role of dedicated structures and spaces of interaction at which various logics meet-sometimes aligning, sometimes compromising, and sometimes clashing. Our empirical approach is based on a multilevel (country, region, and university), longitudinal, historical case study in a Continental European setting, offering an additional specific geographical contribution to the growing international evidence of knowledge transfer policies and practices.

The remainder of our paper is organized as follows. In Sect. 2, we present the data collected and describe how we combined them in our analysis. In Sects. 3, 4 and 5, we report a detailed account of the events and actions examined starting from the national level, moving to the regional level, and concluding at the university level. In Sect. 6, we expand previous sections to discuss the evidence thoroughly, relate it to the three perspectives used, and outline our contributions. We conclude in Sect. 7 by summarizing the results, discussing their limitations, and identifying opportunities for future research.

\section{Data and methods}

We based our analyses on a combination of primary and secondary data, both qualitative and quantitative, regarding policies and practices linked to KTT in Italy from 1996 to 2016, at three levels of analysis: national, regional, and university. We collected our data from archival documents, interviews with key informants, and public databases. We retrieved archival documents from publicly available sources and reports distributed in official meetings. We collected internal working documents and memos of the University of Bologna, the Emilia-Romagna Regional Government, and agencies, through critical informants and the university portal accessible to staff. ${ }^{1}$ We enriched these data by direct observations carried out during the study period by one of the authors, who participated in various capacities in some of the activities described in the paper.

${ }^{1}$ All documents are available from the authors upon request, subject to current privacy regulations. 
We identified critical informants according to the roles played during our period of observation within the Emilia-Romagna region and the University of Bologna. We focused on those in top-level governance roles, those directly managing the various initiatives analyzed, and those who participated in crucial supporting roles that emerged from retrieved documents. We were able to track one-third of the 24 potential informants, thereby offering a balanced view of the different perspectives involved, various roles, and the presence of both the Regional Government and the University. ${ }^{2}$ In total, we collected over $13 \mathrm{~h}$ of interviews. These were recorded and conducted by the first author. She did not know the informants, was not involved in the events, and was, therefore, able to interact and collect the information unbiasedly. We used these interviews to clarify and discuss interpretations of the events in documental analysis, add evidence, and gather additional documents.

We used publicly accessible databases to collect various time series that documented general aspects at the three levels of analysis. We extracted data on patents from the national database Patiris (https://patiris.uibm.gov.it), which was designed and implemented by the University of Bologna in collaboration with the Ministry of Economic Development, to report a census of all Italian patents owned by a university or a national public research institution (PRI). At the national level, we considered the number of patent families of Italian PRIs from 1996 to 2016, starting from the document with the oldest publication date. At the regional and university levels, the data covered the period between 1996 and 2013 and considered the number of patents by application date. We retrieved data on spin-offs from Italian universities and research centers from the Netval's ${ }^{3}$ database (www. netval.it), which covers 1981-2015. We recovered data on the number of start-ups from the Italian Registry of Companies starting from 2013, when a specific section of the registry began recording innovative start-ups. We derived data on start-ups at the regional level from formal reports issued by the Ministry of Economic Development (www.mise.gov.it). Table 1 summarizes these various sources; it includes a list of all items used and where they can be accessed, if publicly available.

We adopted a multilevel, longitudinal, historical case study research approach (Yin 2003). We combined the different documents with various national and regional laws, internal regulations of the University, evidence reported from previous studies conducted in Italy on technology transfer, and reports developed by numerous national and international centers. This combination of collected materials ensured consistent interpretation and highlighted specific aspects to inform the interviews with critical informants. To control for possible biases associated with direct participation in the events (Bansal et al. 2018), we eliminated any detail, event, or interpretation that was not supported by at least one other additional source. In cases with conflicting evidence, we relied solely on sources other than our own direct experience.

Data analysis proceeded in three steps. First, to identify disruptive moments and turning points in policies and practices, we constructed a timeline of significant KTT events at three levels of analysis: national, regional, and university. Second, for each level, we reconstructed a narrative of the events and their relationships, both within and across levels. Third, by combining the evidence that emerged from the different sources, we identified a set of regularities and inconsistencies between the different levels, as well as possible

\footnotetext{
2 The other potential respondents were either deceased, impossible to contact, or unavailable at the time of data gathering.

3 See Sect. 3 for a discussion of the genesis of Netval and its role in the Italian technology transfer ecosystem.
} 
explanations for turning points. We then compared this data over time and across levels of analysis, using a visual mapping strategy to help identify phases, events, actions, and interactions across levels.

Most information that we retrieved relates to two formal mechanisms of knowledge transfer: patents and spin-offs. Some evidence, mainly at the regional level and through accounts provided by our informants, also relates to contract research with private companies and consulting activities; however, we do not have any evidence for other informal mechanisms of technology transfer (e.g., student internships or personnel mobility). Patent data refers to inventions owned partially or totally by a university, but do not include inventions attributed to professors and owned by private companies, or those directly owned by professors. Similarly, spin-off data refers to new companies founded by professors and reported by their university, but do not include companies founded independently by university personnel or companies founded by students. According to results of other studies on informal mechanisms of technology transfer (Nelson 2012) -i.e., patents (Goel and Göktepe-Hultén 2018; Lissoni 2012) and student entrepreneurship (Bergmann et al. 2016; Eesley et al. 2016) — our choice may represent the overall effect of the specific policies described. We do not focus on any specific output or any measure of direct or indirect effectiveness of the different policies described, but on the role of universities in the processes analyzed. We, therefore, privilege the consistency of the data over differing levels of analysis, rather than breadth and variance. In Sect. 7, we refer to studies on these different aspects in Italy to determine the possible limitations of our results.

\section{Evolution of the national context}

\subsection{The Italian university system}

The Italian university system has traditionally relied on a distributed set of public institutions fully funded by the government through the Ministry of Education, Universities, and Research (MIUR) and complemented by a limited number of private institutions formally approved and supervised by MIUR. Before the 1990s, the autonomy of Italian universities was significantly limited. Financially, universities received almost all resources directly from MIUR through yearly transfers dedicated to specific sets of expenses. Dedicated allocations, negotiated directly with central governments, funded new investment and development plans. Faculty recruiting occurred at the national level, and research projects were funded almost exclusively through national budgets.

Between 1989 and 1995, a series of reforms introduced some autonomy for universities and paved the way for a more diversified and competitive system (Paletta 2004). Law $168 / 1989$, which specified various types of autonomy and provided the normative foundations for their implementation, shifted authority from central to local governments and significantly increased universities' autonomy over the level and degree of potential differentiation (Polifroni 2016). Normative autonomy gave universities the power to create their statutes of incorporation as their main internal regulatory framework and organize their activities through a system of internal regulations. Organizational autonomy made the universities solely responsible for defining their internal procedures and norms. Both forms of autonomy, although introduced in 1989, took eight more years to be fully deployed, with the publication of Ministerial Decree D.M. 95/1996. Financial and managerial autonomy, formally introduced by Law 537/1993, gave universities full control over their financial 
Table 1 Data sources

Archival data

Official documents publicly available
Law of 9 May 1989, n. 168. "Establishment of the Ministry of University and Scientific and Technological Research"

Law of 24 December 1993, n. 537. "Public finance corrective actions"

MIUR Note of 5 November 1996, protocol n.50 "Statutes of Autonomy",

Legislative Decree 27 July 1999, n. 297 "Reorganization of the discipline and streamlining of procedures for supporting scientific and technological research, for the dissemination of technologies, for the mobility of researchers"

Law of 30 December 2010, n. 240 "Rules regarding the organization of universities, academic staff and recruitment, as well as the Government's delegation to promote the quality and efficiency of the university system"

D. M. 10 August 2011, n. 168. "Regulation concerning the definition of the criteria for the participation of university professors and researchers in companies with spin-off characteristics or university start-ups in implementation of the provisions of article 6, paragraph 9, of the law of 30 December 2010, n. 240"

Law Decree of 18 October 2012, n. 179 "Further urgent measures for the growth of the country"

Law of 17 December 2012, n. 221 "Conversion into law, with amendments, of the law decree 18 October 2012, n. 179, bearing further urgent measures for the growth of the country"

Ministerial Decree of 30 January 2013 n. 47 "Decree for selfassessment, initial and periodic accreditation of venues and courses and periodic assessment"

ANVUR Biennial Report on the state of the University and Research System 2018

Regional Law 14 May 2002 n.7

PRITT 2003-2005 Implementation of the Regional Law 14 May 2002 n. 7

Report: Implementation of the first Regional Program for Industrial Research, Innovation and Technology Transfer PRITT 2004-2005

Regional Operational Program FESR 2007-2013 Emilia Romagna Region

Resolution of the Regional Council n.736 of the 19th May 2008, POR FESR 2007-2013. Adoption of guidelines for implementation activity I.1.1 "Creation of Tecnopoli for the industrial research and technology transfer"

Regional program of productive activities and regional program for industrial research, innovation and technology transfer 2012-2015

Regional Operational Program FESR 2014-2020 Emilia Romagna Region 
Table 1 (continued)

\begin{tabular}{|c|c|}
\hline & $\begin{array}{l}\text { Memorandum of Understanding between the Emilia-Romagna } \\
\text { Region, the Universities of Bologna, Ferrara, Modena and Reg- } \\
\text { gio Emilia, Parma, the Milan Polytechnic and the Catholic Uni- } \\
\text { versity of Milan (Piacenza headquarters), the CNR, the ENEA, } \\
\text { the Rizzoli Orthopedic Institutes, for the development of the } \\
\text { High Technology Regional Network in the implementation of } \\
\text { the Strategic Objective } 1 \text { of the POR FESR 2014-2020, of the } \\
2012-2015 \text { PRRIITT and of the consortium agreement for the } \\
\text { activities of the consortium company for ASTER actions }\end{array}$ \\
\hline & $\begin{array}{l}\text { Emilia Romagna Annual Implementation Report } 2016 \text { POR } \\
\text { FESR 2014-2020-Summary for the citizens (June 2017) }\end{array}$ \\
\hline & University of Bologna Strategic Plan 2007-2009 \\
\hline & University of Bologna Strategic Plan 2010-2013 \\
\hline & University of Bologna Strategic Plan 2013-2015 \\
\hline & University of Bologna Strategic Plan 2016-2018 \\
\hline Reports distributed in official meetings & $\begin{array}{l}\text { Reports issued by the Ministry of Economic Development-data } \\
\text { on start-ups at regional level }\end{array}$ \\
\hline \multirow[t]{6}{*}{ Internal official documents } & $\begin{array}{l}\text { Spinoff Regulation-Rectoral Decree } 6 \text { June 2002, No. } 180 \\
\text { BU n.87 15/06/2002 }\end{array}$ \\
\hline & $\begin{array}{l}\text { Memorandum of understanding between the Emilia-Romagna } \\
\text { Region, the Universities of Bologna, Ferrara, Modena and } \\
\text { Reggio Emilia, Parma, the CNR, Enea, the Polytechnic and the } \\
\text { Catholic University of Milan for the Piacenza offices, for the } \\
\text { realization of the High Technology Regional Network in the } \\
\text { Axis implementation I Activities } 1.1 \text { of the 2007-2013 POR } \\
\text { FESR, and of the consortium agreement for the activities of the } \\
\text { company Aster }\end{array}$ \\
\hline & $\begin{array}{l}\text { Strategic guidelines and operational policy on the subject } \\
\text { ofpromotion of new entrepreneurship and spin-offs in the Alma } \\
\text { Mater Studiorum-University of Bologna-November } 2013\end{array}$ \\
\hline & Alma Cube Consortium Contract modified in 2007 \\
\hline & $\begin{array}{l}\text { Regulation on industrial and intellectual property of the Univer- } \\
\text { sity of Bologna (Rector's Decree N. } 269 \text { of 15th April 2014, } \\
\text { Official Bulletin No. } 212 \text { of 15/04/2014) }\end{array}$ \\
\hline & $\begin{array}{l}\text { Guidelines for the assessment of the university research } \\
\text { (approved by the Board of Directors on March 25th } 2014 \text { and } \\
\text { later updated on February 24th 2015) }\end{array}$ \\
\hline Internal working documents & $\begin{array}{l}\text { University of Bologna-Minutes of the Academic Senate of } \\
\text { December 14, 2009-Resolution on Tecnopoli Memorandum } \\
\text { of Understanding }\end{array}$ \\
\hline Internal memos & Final report Tecnopoli Committee (22/12/2008) \\
\hline \multirow[t]{9}{*}{ Websites } & ANVUR (https://www.anvur.it/) \\
\hline & Ministry of Economic Development (www.mise.gov.it) \\
\hline & PNICube (https://www.pnicube.it) \\
\hline & Roars-Return On Academic ReSearch Blog (www.roars.it) \\
\hline & $\begin{array}{l}\text { Gaetano Marzotto Award (https://www.premiogaetanomarzott } \\
\text { o.it) }\end{array}$ \\
\hline & High Technology Network (https://www.retealtatecnologia.it) \\
\hline & Spinner Consortium (https://www.spinner.it/) \\
\hline & $\begin{array}{l}\text { Smart Specialization Strategy Emilia-Romagna (https://www. } \\
\text { aster.it/s3-smart-specialisation-strategy-emilia-romagna) }\end{array}$ \\
\hline & University of Bologna (www.unibo.it) \\
\hline
\end{tabular}


Table 1 (continued)

\begin{tabular}{|c|c|}
\hline & World University Ranking (www.topuniversities.com) \\
\hline & CENSIS (www.censis.it) \\
\hline & AlmaOrienta https://almaorienta.unibo.it) \\
\hline & AlmaEClub (https://almaeclub.unibo.it/en) \\
\hline & Basement Club (https://site.unibo.it/basementclub/it) \\
\hline & CesenaLab (https://www.serinar.unibo.it/cesenalab/) \\
\hline & UNIBO Magazine (https://magazine.unibo.it) \\
\hline & StartUp Day (https://site.unibo.it/startupdayunibo) \\
\hline \multirow[t]{8}{*}{ Public databases } & Patiris (https://patiris.uibm.gov.it)—data on patents \\
\hline & Netval (www.netval.it)—data on spinoffs \\
\hline & $\begin{array}{l}\text { Ministry of Education, Universities and Research Statistics (https } \\
\text { ://dati.ustat.miur.it) }\end{array}$ \\
\hline & Italian Registry of Companies-n. of startups \\
\hline & $\begin{array}{l}\text { Data from Eurostat-Regional Science and Technology Statistics, } \\
\text { elaborated by the Emilia-Romagna Region Statistical Service } \\
\text { and published at https://statistica.regione.emilia-romagna.it/ } \\
\text { factbook }\end{array}$ \\
\hline & National Students Register (https://anagrafe.miur.it/index.php) \\
\hline & $\begin{array}{l}\text { Portal of higher education data of the Italian Ministry of Educa- } \\
\text { tion, University and Research (https://dati.ustat.miur.it/dataset) }\end{array}$ \\
\hline & $\begin{array}{l}\text { Ministry of Education, University and Research https://www. } \\
\text { istruzione.it/archivio/web/universita/home.html }\end{array}$ \\
\hline \multicolumn{2}{|l|}{ Interviews } \\
\hline Tot. hours & 13 \\
\hline N. of people interviewed & 8 \\
\hline
\end{tabular}

resources and allocations. This law introduced and mandated the independent control body, known as Nucleo di Valutazione, charged with monitoring and assessing the efficacy of university choices. Law 341/1990, Law 127/1997, and D.M. 509/1999 reformed teaching and scientific autonomy, to align university practices with the changing European landscape.

These reforms profoundly affected the way Italian universities developed their technology transfer practices. The reforms allowed universities to introduce a diversified set of internal norms and regulations to create new practices and opportunities that had been impossible under the previous regulatory system. During the following decade, university performance measurement accompanied the higher level of autonomy, gradually shifting the whole system from a block grant to a competitive funding model. Between 1998 and 1999, the National Research Evaluation Steering Committee (CIVR) and the National Committee for the Evaluation of the University System (CNVSU) started to operate as central monitoring agencies, introducing an articulated set of actions and accountability obligations. The first national research evaluation exercise was launched and completed in 2006, focusing on academic publications released between 2001 and 2003, and voluntarily disclosed by universities. Although some universities incorporated the results into their internal policies, it did not have a significant impact on national-level allocations.

In 2006, the introduction of the National Agency for the Evaluation of the University and Research Systems (ANVUR) further reformed the entire monitoring and evaluation system, paving the way for a performance-based allocation system for the distribution of 
national resources. The Agency became responsible for assessing research, teaching, and third mission activities. It began operations in 2010 and instigated Law 204/2010, which introduced a tenure-track system, modified the roles and recruitment procedures for academic positions, rebalanced the roles and competencies of the governance bodies (boards of directors and academic senates), and other more specific changes. After almost 2 years of intense debates and strong opposition by faculty, students, and staff all over the country, the Parliament approved the reform in December 2010 (Capano et al. 2016).

In 2012, ANVUR launched a subsequent evaluation round with a longer, 5-year window (2004-2010) to implement self-assessments, periodic evaluations, and an accreditation system introduced by the 2010 university reform. The goals of this effort were to periodically certify each teaching program at universities, assess research productivity in all active disciplines, and allocate a (growing) portion of the yearly national budget. As similar studies have documented (e.g., Elton 2000), the new assessment exercise generated fierce debate on the assessment's merits and limits and the risk of driving research toward shortterm publication goals rather than longer-term, ambitious projects (Abramo and D'Angelo 2015). Overall, however, it increased attention on research productivity (Capano and Turri 2017). ANVUR also began to collect information about a wide range of KTT activities, ranging from the management of archaeological sites and museums to university Start-ups. However, ANVUR relied on self-reported data and mainly collected descriptive accounts rather than structured and reliable data.

In 2013, in preparation for the third research assessment covering 2011-2014, ANVUR set up an expert panel to define a set of indicators to track KTT success, mostly at the university level and improve the previous procedure (ANVUR 2015). The group recommended collecting the information reliably before using it in the evaluation process. Despite this recommendation, MIUR included KTT activities among those used to determining yearly budget allocations (MIUR, D.M. 47/2013). As a result, the third evaluation of the quality of research (VQR), carried out in 2015, mandated technology transfer activities be measured and reported.

At this time, opposition to the excessive use of numbers and indicators in VQR heightened. A community of opponents gathered on ROARS (www.roars.it), a blog that began during the 2004-2010 evaluation. Although criticism initially centered around the general concepts of research assessments and the evaluation techniques, it grew to include various governments' policies on research matters.

Between 2012 and 2016, a set of Ministerial Decrees introduced different parts of the 2010 reform. During our period of observation, several significant changes occurred at the institutional level and involved the entire university system. However, we limit our exploration to specific elements related to KTT practices. To fully understand our analysis, it is essential to consider two other factors: the overall funding of the university system and the evolution of the human capital bases of universities. Under the pressure of macroeconomic weaknesses that continue to characterize Italy (The Economist 2017), all governments between 1999 and 2014 reduced funding for universities and PRIs. As Table 2 shows, the primary source of funding (FFO) transferred yearly by the MIUR to universities decreased in nominal terms and even more so in real terms. At the same time, the funding mechanisms dedicated to research diminished in variety and amount, and calls were opened irregularly over the years. Funding pressures resulted in a reduced capacity to hire new faculty and replace retiring faculty. One of the general measures adopted to decrease public spending was to reduce the number of civil servants employed, universities/PRIs personnel included. Moreover, professors and staff wages did not increase between 2011 and 2015, including seniority increases embedded in previously approved contracts. This generalized 


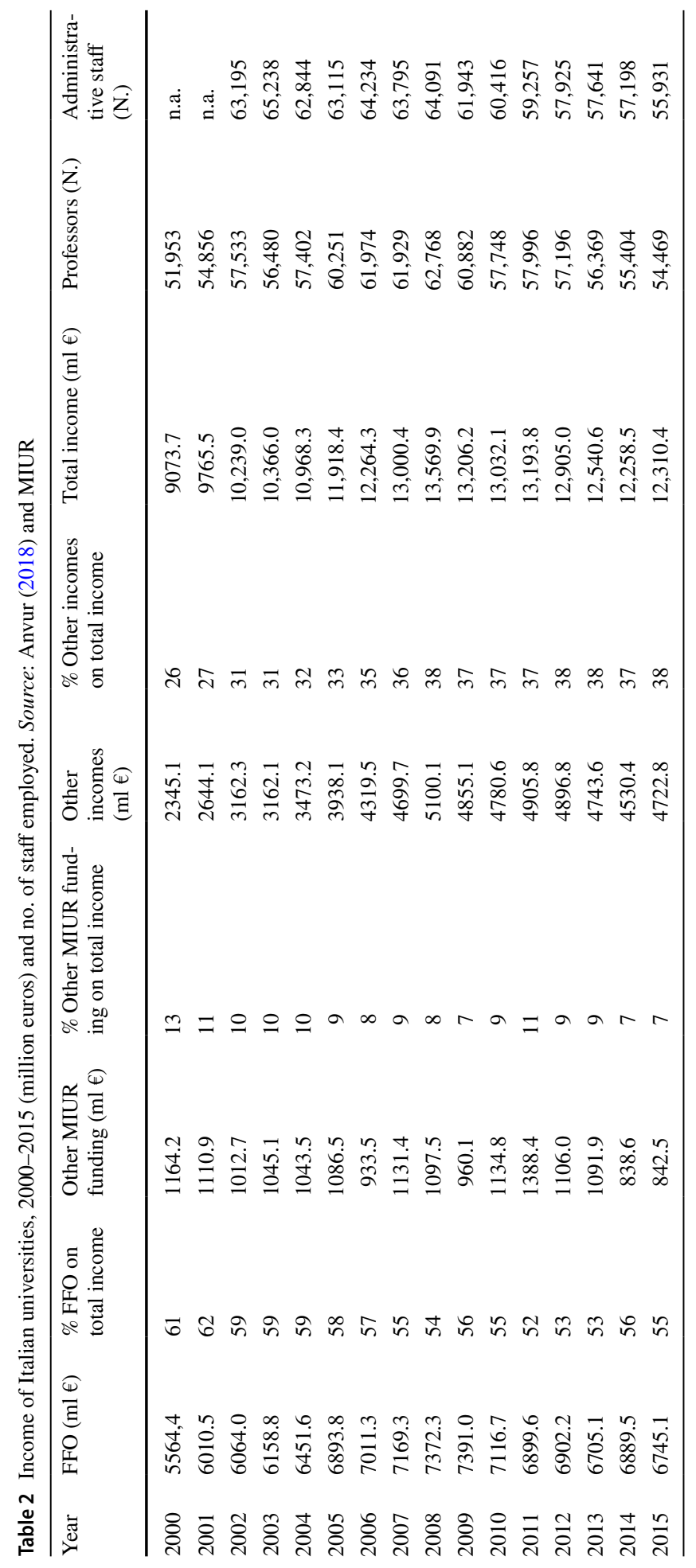


pressure on resources and the increased level of autonomy-along with the limitation of tuition to $20 \%$ of the total yearly university budgets-led to an attempt to secure alternative funding.

\subsection{Universities' autonomy and KTT practices}

During the last decade of the twentieth century, KTT models and practices experienced growth in both theoretical and empirical interest. The United States' 1982 Bayh-Dole Act (Audretsch 2014; Siegel and Wright 2015), relevance attributed to National Innovation Systems (Nelson 1993), and development of the triple helix concept (Etzkowitz et al. 2000) drove the first wave of attention to KTT. The growing debate quickly generated significant impacts on the evolution of laws, regulations, organizational attention, and tools and initiatives in different parts of the world. Italy was no exception (Cesaroni and Piccaluga 2016; Fini et al. 2011; Grimaldi et al. 2011), despite the significant limitations faced by universities and PRIs in their freedom to develop, protect, manage, and exploit research results (Lissoni et al. 2013; Serafini 2011). From our perspective, two aspects are particularly relevant to Italy: intellectual property rights (IPRs) and spin-offs. In other parts of the world as well, these topics were the first to be targeted by national legislation (Lissoni 2012; Van Looy et al. 2011).

The legal foundations of university patents date to the 1939 national patent law, but it was only after 1996 that universities started creating mechanisms to commercially exploit research results (Baldini et al. 2014). The trigger was universities' implementation in 1992 of a self-administration regime that followed financial and accounting autonomy. In 2001, the newly elected center-right government amended existing intellectual property (IP) law, introducing professors' privilege and shifting IP rights from universities to faculty members. This decision followed the deregulation of state intervention in entrepreneurial activities (a primary element in the electoral campaign). Additionally, it went in the opposite direction from many reforms implemented around the world that abandoned professors' privilege to fully empower the technology transfer activities of universities (Lissoni 2012).

The professors' privilege intended to provide professors and researchers with more significant incentives to exploit their research financially. However, it ended up increasing the discrimination between public and private researchers, the complexity of university-industry interactions, and decreasing universities and research organizations incentives to strategically manage inventions developed within their laboratories (Balconi et al. 2004; Baldini et al. 2006; Breschi et al. 2008). The reform occurred at a time when several prominent Italian universities had already developed specific IP-related policies and strategies (Baldini et al. 2014). It is not surprising that a public debate arose involving various actors, such as industry associations, universities, and PRIs. As a result, universities joined forces with an agreement in 2002 to establish common strategies enabling technology transfer processes to move forward. An informal network, known as Netval, was created. The network started organizing training activities aimed at sharing the competencies of member universities and defining standard procedures and criteria about the public research exploitation process. At the end of 2006, the network was transformed into an association, representing 60 universities. Its purpose was to develop technology transfer in Italy, support networking among TTOs, and offer training courses to strengthen competencies. In 2005 (and partly as a consequence of institutional mobilization and the recognition that professors' privilege had not improved the economic exploitation of inventions), Law 10/2005 modified the 
existing regime, eliminating the privilege for inventions stemming from research at least partly financed by external funds (the vast majority of cases).

This interplay of national regulation, institutional efforts promoted at the university level, and bottom-up initiatives developed by interested communities also applied to spinoffs. Law 297/1999 was the first national legislation to introduce the notion of spin-offs. It defined spin-offs as companies that exploit research results for industrial use and that include participation of research staff employed by research institutions (including universities). ${ }^{4}$ According to the Law, universities and PRIs could decide whether and how to regulate researchers' and professors' founding, owning, and managing of spin-offs, as well as how to regulate IPR distribution and conflicts of interest. This regulatory framework evolved over the years until the 2010 national reform of universities, and the subsequent D.M. MIUR 168/2011 introduced the obligation of universities to regulate these activities according to a general framework provided by the MIUR.

In 2000, the Polytechnic of Turin and the University of Bologna launched the country's first business plan competitions, targeting spin-offs that originated in university communities. In 2003, they joined forces with the University of Padova, the University of Udine, and the Polytechnic of Milan, which had started their competitions. The group launched the first edition of the national contest among the winners in local competitions, known as the National Award for Innovation (Premio Nazionale dell'Innovazione, PNI). Subsequently, the number of initiatives to foster new entrepreneurial initiatives through a combination of training, team-building, seed capital, networking, and start-up services, grew around the country, as did attempts to combine competitions on a larger scale. In 2003, the Ministry of Productive Activities financed the IUNet project, presented by the newly founded Association of University Incubators (Associazione Incubatori Universitari, AIU) to create a network among university business incubators. In 2004, AIU collaborated with PNI to create PNICube, an association of universities aimed at stimulating the birth of new enterprises with a high level of university knowledge and accompany them to market (https ://www.pnicube.it/chi-siamo/). Today, PNICube has 44 members and is the promoter of two important initiatives: the National Award for Innovation and the Italian Master Startup Award (IMSA). More recently, a private initiative supported by the prominent Marzotto family of Italian entrepreneurs launched a nation-wide campaign acting as a powerful catalyst for several different initiatives (https://www.premiogaetanomarzotto.it/it/home/).

Although the level of attention to entrepreneurial initiatives nourished within the "ivory towers" (Chiesa and Piccaluga 2000; Colombo et al. 2010), the policy debate on the more general role and importance of start-ups in rejuvenating the Italian economy did not gain momentum until the end of the 2000s. It was only in 2012 that Law 221/2012, a set of urgent measures for enhancing the growth of the country, focused on innovative start-ups and incubators and introduced a set of relevant provisions to support their birth, financing, and growth. It introduced a new form of limited liability corporation named "innovative start-up." For these companies, the law introduced a favorable tax rate, a special tax regime with dedicated incentives for private and professional investors, the possibility to remunerate work and services with shares, and a simplified failure procedure. To be eligible, companies must hold some form of IPR, or at least two-thirds of its employees must hold Masters of Science or PhDs, or invest at least $15 \%$ of its turnover in R\&D. The law also approved the set-up of a special session of the Register of Companies, instituting

${ }^{4}$ Law 297/99, art. 2 comma 1 letter e). 




No. of patent families from Italian No. of patent families from Italian
public universities and research centers (year of publication)

Source: Patiris 2018

No. of spin-offs (foundation year)

Source: Spin-off Italia (Netval 2018)

2500

2000

1500

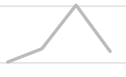

No. of innovative start-ups

Source: Italian Registry of Companies 2018

1000

500

0

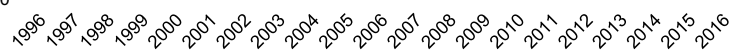

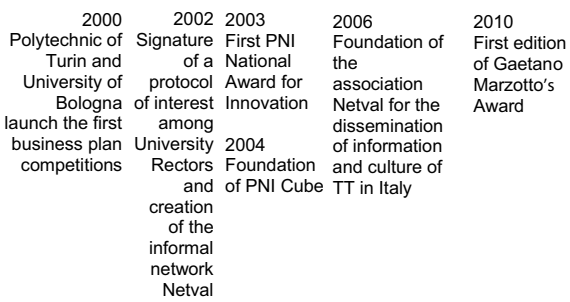

Fig. 1 Knowledge transfer policies and practices at the national level

mandatory registration for innovative start-ups and incubators willing to take advantage of the benefits introduced by the law (and its subsequent minor changes, introduced in 2013, 2014, and 2015). The same law introduced the first national regulation of equity crowdfunding to collect risk capital for innovative start-ups. The Innovative Start-Up Register soon started to be populated by many university spin-offs (Bolzani et al. 2014).

Figure 1 depicts how policies and practices unfolded at the national level between 1996 and 2016. It shows trends in patents, spin-offs, and innovative start-ups, corresponding 
to the enactment and interplay of national laws, university regulations, and bottom-up initiatives.

\section{Three waves of innovation policies in Emilia-Romagna and the role of local universities}

The Emilia-Romagna region, with a population of around 4.5 million people and nine cities inhabited by more than 100,000 residents, is the sixth-largest region in Italy. With over 400,000 companies, mainly SMEs, it has a strong foothold in manufacturing (Unioncamere 2018). It is among the leading economic regions of Europe with R\&D expenditure far higher than the national average $(1.8 \%$ of the GDP vs. $1.3 \%),{ }^{5}$ and a highly qualified human-capital base. ${ }^{6}$

The innovation capacity of regional companies also reflects the specificities of regional supply chains noted by many scholars: the degree of specialization of production facilities, technicians and workers, fostering the presence of high-level problem-solving skills (Piore and Sabel 1984), presence throughout regional territories, easing the existence of technological interdependencies, vertical integration, contamination within production chains, and networking of complementary skills (Becattini et al. 2009). Because of these characteristics, large, complex industrial chains have developed in the territory, transforming traditional industrial districts into more contemporary regional clusters (Belussi et al. 2010; Cainelli and Zoboli 2004; Humphrey and Schmitz 1998; Morosini 2004).

Four universities have their main campuses in the Emilia-Romagna region: the University of Parma, the University of Modena-Reggio Emilia, the University of Ferrara, and the University of Bologna. The Polytechnic University of Milan and the Catholic University of the Sacred Heart have branches in Piacenza, and Johns Hopkins School of Political Studies has a branch in Bologna. Moreover, the University of Bologna has branches in various towns in the eastern part of the region (Imola, Forlì, Cesena, Faenza, Ravenna, and Rimini). The region hosts local branches of several national research institutions (National Research Council CNR, Italian National Agency for New Technologies, Energy and Sustainable Economic Development ENEA, National Institute for Nuclear Physics INFN, Italian Institute of Technology IIT). At the end of 2016, there were 142,241 university students enrolled in Emilia-Romagna (55.82\% at the University of Bologna) and 8537 professors and researchers (more than half involved in science, technology, engineering and mathematics disciplines) employed by its universities. ${ }^{7}$ Figure 2 shows the distribution of students and researchers across the four universities.

The regional level innovation policies introduced in the period under examination built on the highly dynamic entrepreneurial system already present in the region to maintain and increase the specialization level of the production system. The creation of a regional innovation ecosystem that promoted strong relationships between dynamic business systems

\footnotetext{
${ }^{5}$ Data from Eurostat-Regional Science and Technology Statistics, elaborated by the Emilia-Romagna Region Statistical Service and published at https://statistica.regione.emilia-romagna.it/factbook/fb/rs/inv_at.

6 Data from Eurostat-Regional Science and Technology Statistics, elaborated and published online by the Emilia-Romagna Region Statistical Service and published at https://statistica.regione.emilia-romagna.it/ factbook/fb/rs/cap_umano.

7 Data elaborated by the authors from the National Students Register (https://anagrafe.miur.it/index.php) and the portal of higher education data (https://dati.ustat.miur.it/dataset/2002-2008-personale-universitario and https://dati.ustat.miur.it/dataset/2016-personale-universitario) of the Italian MIUR.
} 


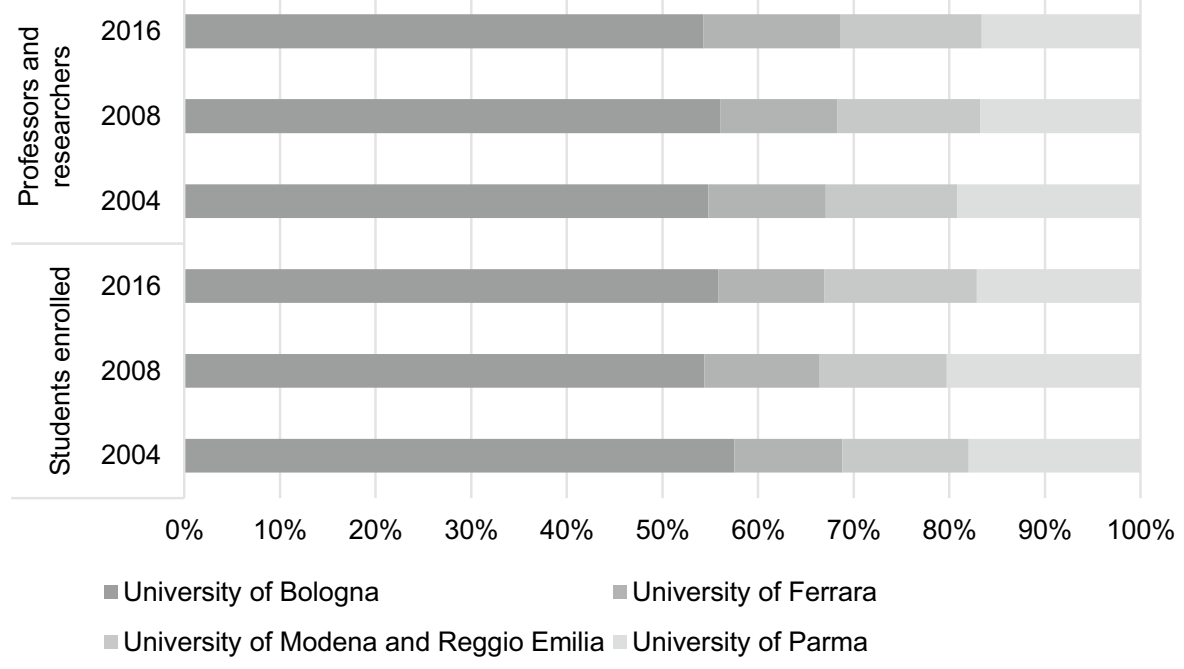

Source: Italian Ministry of Education, University and Research, 2018

Fig. 2 Professors, researchers, and students at Universities in Emilia-Romagna

(with high levels of technological innovation and complex supply chains) and research and innovation and training centers linked all phases of the policy. The three common elements of the various programs were strengthening the regional IPR system, promoting innovative start-ups, and supporting human capital development.

In 2001, the Italian Government introduced a major constitutional reform to rebalance the national and regional governments' power. ${ }^{8}$ By favoring the implementation of active policy interventions focused on regional specificities, the reform paved the way for a series of regional laws targeted to different areas, including tourism, welfare, the environment, and industrial policy. Moreover, by taking advantage of these new opportunities, the Emilia-Romagna Government was the first Italian Regional Government to develop and promote a regional system for industrial research, innovation, and technology transfer. The universities, research centers, business associations, and the Regional Government decided to collaborate to sustaining a direct relationship between research providers and knowledge users and founded in 2001 the public Agency for Technological Development of Emilia-Romagna (ASTER). It was incorporated as a new entity involving the Regional Government; the five regional universities (Bologna, Modena, Reggio Emilia, Parma, and Ferrara, later joined by the Polytechnic University of Milan and the Catholic University of the Sacred Heart, through their branches in Piacenza); the Italian National Research Council (CNR); the Italian National Agency for New Technologies, Energy and Sustainable Economic Development (ENEA); the Chamber of Commerce; and other business associations. The partnership, inspired by the concept of the triple helix (Etzkowitz et al. 2000), became a reference point for the coordination of regional actors and mechanisms that transfer knowledge to industry. Subsequently, in 2002, Regional Law 7/2002 - "Promotion of

\footnotetext{
8 The reform did not include five of the 20 regions (Valle d'Aosta, Trentino-Alto Adige, Friuli VeneziaGiulia, Sardinia and Sicily) that have always operated with greater autonomy, for historical reasons that date to the 1948 Constitution and the founding of the Republic of Italy.
} 
the Regional system of industrial research activities, innovation, and technological transfer"- - provided the normative foundations for an articulated regional innovation. The Law set general objectives for the competitive development of the Emilia-Romagna system, encouraging companies' access to the structures and skills of local research and knowledge production system, and the economic exploitation of research, including the creation of new businesses and start-ups.

The Regional Program for Industrial Research, Innovation, and Technological Transfer (PRRIITT 2003-2005), included within the Regional Triennial Program for Productive Activities (2003-2005), represented the first set of supporting actions based on a competitive evaluation process. It had a two-fold aim: to support company investments in business research and foster a new supply of knowledge coming from universities and other research institutions in collaboration with the business system. The medium-term goal was to strengthen both the supply and the demand sides of the regional innovation system with new investments and improve its overall impact by building a strong network of relationships among public and private actors and the Emilia-Romagna High Technology Network. The process was supervised and managed by an Expert Committee composed of five industry and academic leaders. It deployed three lines of activity. The first one supported the development of companies' new products and services in collaboration with universities and PRI. The second one supported new research and technology transfer laboratories (Labs) promoted by universities for the development of applied research. The third launched innovation centers (Centers) focused on the development of technology transfer programs for specific industries. ${ }^{9}$ All funding instruments that targeted the supply side (universities and IPR) were intended to support the start-up of new Labs and Centers, but it soon became clear that the newly funded initiatives needed further financial support from the Regional Government to continue their operations. ${ }^{10}$

The regional policy development process, therefore, turned to a new phase. The consolidation and further integration of the High Technology Network followed a top-down approach. It focused on the connection of Labs and Centers into larger technological areas, aggregating the leading supply chains and specializations of the region. Although no new resources were available at the national level, an EU-based budget was available to support innovation policies at the regional level. The 2007-2013 plan targeted the coordination of the network research capacity with areas of specialized production, including agri-food, construction, energy and environment, information and communications technology (ICT) and design, mechanics and materials, and life sciences. Regional funding then shifted from investment in people carrying out research activity to hard investments in infrastructures.

New research infrastructures, known as Tecnopoli, were introduced and identified as an addition to the High Technology Regional Network. ${ }^{11}$ Tecnopoli were initially envisioned as new legal entities, with dedicated research capacity and facilities, relying on a combination of professors and researchers employed by regional universities and PRIs, and newly hired younger researchers who would specialize in technology transfer and industrial

\footnotetext{
9 The PRRIITT 2000-2005 defined the strategic guidelines, implementation criteria, and priorities for the implementation of the actions included in Regional Law n. 7/2002.

10 From interview of Informant 8 (Emilia-Romagna Region).

11 Resolution of the Regional Council n.736 of the 19th May 2008, POR FESR 2007-2013. Adoption of guidelines for implementation activity I.1.1 "Creation of Tecnopoli for the industrial research and technology transfer."
} 
research. These dedicated physical locations had to house Labs and Centers that were part of the network, as well as host spin-offs and high-tech companies, with ASTER playing the role of network coordinator. They were the physical access points for companies providing opportunities for fostering communication with regional universities. The lack of flexibility and excessive bureaucracy of the university administrative procedures that were perceived to be endangering relationships with industry guided the development of new research centers. It lead to the definition of a governance model in which the universities would participate remaining independent from their administrative apparatus. The idea intended to accommodate the Regional Government's need for increased political credibility by making the results of its policy more visible. As one of our informants reported:

One of the things...about which the Regional Ministry [for Productive Activities] was very upset was: I want a plaque. I mean, I want something that visible. I want a place where it says: Here we do these things. Because otherwise you don't exist. So, of course, this is the point of view of someone who must somehow also justify the use and investment of public money. (Informant 7, ASTER)

The German Fraunhofer network model was mentioned explicitly in several discussions and documents. Reference to this model generated intense debate within the university community. On the one hand, smaller universities were struggling because of the decreasing level of national funding (see Sect. 3.1) and their limited success in accessing EU grants. On the other hand, the opportunity to obtain regional funds to buy equipment and hire research personnel had to be weighed against the prospect of increased Regional Government control of universities' activities and the need to dedicate a significant number of faculty and equipment to co-finance Tecnopoli. This dilemma occurred at a time when KTT was not considered in the assessment of university performance and competitive funding allocation procedures (see Sect. 3.1).

For a university, freedom of research is beyond question. I mean, you [the Regional Government] can tell me: I have a problem to solve. You cannot tell me how I get there, because this is my job, to understand how I get to this goal that you have set for me. So there might have been difficulties in understanding the fact that when you [the university] are working...for another subject [the Regional Government], you still need to be sure that this subject gives you some guidelines but it doesn't force you to assume [certain actions]. Because, then, this can also turn into pressures to work more in a certain sector rather than another and so on. (Informant 6, University of Bologna)

The university requested to do all the work at no cost, including all direct and indirect expenses.... Which means that if I have an office where I do industrial research activities financed by that plan, the heating, cleaning, net, utilities must all to be included in the financing. That is, they must be covered by [Regional] funds....In other words, the University of Bologna was afraid that through those funds new things would have started and then the university itself had to take charge of this, and therefore it would have been a cost at the end of the project.... On the other hand, the Region was afraid that the University of Bologna would take those [funds] and put them in the cauldron of the university spending at its pleasure. (Informant 4, University of Bologna)

Local city governments were also part of this debate. They counted on new buildings and physical infrastructures to leverage innovation-based investments and pursue urban planning initiatives at times of severe reduction of central government transfers to city budgets. In 2008, the Regional Government initiated a negotiation process with 
universities, research institutions, and major cities to define and detail program implementation procedures. The Regional Ministry for Productive Activities replaced the role played by the Expert Committee in the previous phase. He acted as the orchestrator of bilateral agreements between the Regional Government and various institutions. Although actors seemed ready to converge, largely attracted by the over 300 million euros of public funding, the University of Bologna voiced its skepticism:

With the Rector of [the University of] Bologna...there was a bit of tension, because he said that the Region was...taking the liberty to impose to the university its organizational configuration (Informant 8, Emilia-Romagna Regional Government).

The new Regional Government plan, which committed people and resources to local programs, conflicted with a set of dedicated investments the university had put in place for supporting its faculty in the attraction of competitive research funding. Moreover, the direct relationship between the Regional Government and various research groups, soon created fragmentation in the negotiation, in which the groups' interests did not align with overall university interests and strategic plans:

There was a period in which I clearly remember confrontational phone calls [from the Regional Ministry for Productive Activities], in which he was requesting to have a single contact point...inside the university.......What [the Ministry] did not accept, however, was that he was in charge of productive activities, so a professor would come at a time to present his project to improve production activities. The real reason was the difficulty of understanding. And so, he... asked with a certain...firmness, especially to the Rector....I remember the phrase he used, [the Ministry] called me and said: ... with what hat did Professor X come yesterday to me? What did he mean: Did he come for himself or did he come because the Rector sent him? (Informant 6, University of Bologna)

Any plan in the region without full commitment and participation of the University of Bologna would have been ineffective due to its size, visibility, and resources. However, it would have lacked credibility given local/national influence, reputation, and the role played in numerous bodies and institutions.

These games of policies and practices, which we will discuss in Sect. 5, changed the initial plan envisioned at the regional level, allowing universities to participate in the new Tecnopoli plan through internal units. Those boundary-spanning entities intended to reconcile differing demands and institutional logics (Tracey et al. 2011; Villani et al. 2015) within the University of Bologna. They took the form of Interdepartmental Centers for Industrial Research (CIRIs) and were replicated by other universities in the region. The academic intention was to spin-off from industrial research and technology transfer activities occurring within their departments. The ambition was to target the needs of regional companies better and to gather the various disciplines needed for this to happen - thereby integrating activities that otherwise would have been fragmented and separated because of traditional disciplinary boundaries. The Regional Government allowed universities to keep people and resources under their direct responsibilities and control. It accepted to weaken the boundaries between university departments and CIRIs and the related ambiguity of the funding usage.

In reality there had been a retreat. Originally the Region wanted that these research groups were spun-off. That is, taken out, even if they had to remain under some university influence by using independent Consortia as a legal option..... This was our 
proposal. But then we had to compromise. New industrial research centers were started, in most cases within the university and distinct from the Departments. With their own mission, their own governance, more or less identified. Even if...the definition of the boundaries between Departments and centers has always been a bit problematic. A business proposal arrives at the university: the center takes it, the Department takes it...that is it...it is not clear at all how separated they are from each other. (Informant 8, Emilia-Romagna Regional Government)

This not only meant that [the University] did not mobilize new resources, but that they [received funds] as a university and not as a third party, giving us the difficulty of interpreting how this money had been spent. Because when we ask to monitor the use of the funding, this is still a problem. We cannot be fully sure that these things were done by staff from one CIRI, or by staff not from another or from a Department. (Informant 7, ASTER)

All bilateral agreements between the Regional Government and each university and major PRIs were signed between 2009 and 2010. The agreements defined the type of commitment each institution was going to provide within the Emilia-Romagna High Technology Network. Although the Regional Government abandoned its initial plan to develop a separate research infrastructure under its control through ASTER, the investment for building Tecnopoli in various provinces moved forward, as did the related urban development portion of the plan. Regional universities participated in different ways in the Tecnopoli established in their territories of reference. Only some of University of Bologna's research groups participated in local Tecnopoli activities, pushed mainly by professors' and researchers' commitments and without the formal, direct involvement of the University as a whole. ${ }^{12}$ In the city of Bologna, there were significant delays in the building of the local Tecnopolo's structure, adding opportunities to keep the level of ambiguity high. As one of our informants claimed:

The idea [of Tecnopoli] is there, it is being implemented. The only one that has problems because it is a big project...is the Tecnopolo of Bologna. But Modena, Reggio Emilia, Parma, Piacenza, Rimini, Ravenna, Ferrara, Forlì, and Cesena all have, let's say, these structures. Obviously, this is a useful and necessary step, but not sufficient,.... [The fact that the University of Bologna had to move its equipment to another place] wasn't very welcome .... Well, now, for Bologna we'll see....UNIBO [The University of Bologna] has made some passive resistance also playing on the fact that the Tecnopolo [of Bologna] took longer than the others [to be built]. Because in short it is a very large structure, 100,000 square meters, it requires a lot of money and a lot of time .... Now finally...the works have started....And there is also a part that has been maintained [for the University of Bologna], so as to involve all the CIRI ....For the moment I think only one [CIRI will move there]. But you know how the university is, it may be that once the works are finished, they will all move. You never know, in short. (Informant 8, Emilia-Romagna Regional Government)

During this second phase, between 2007 and 2013, particular attention was paid to new high-tech companies with dedicated investments supporting the launch of new business

\footnotetext{
12 As one of the managers of ASTER showed us during an interview, the University of Bologna's logo does not appear on the website of the High Technology Network in any of the Tecnopoli developed in its territory of competence (https://www.retealtatecnologia.it/la-rete-alta-tecnologia).
} 
ideas. It introduced a set of services for early stages, a Venture Fund launched by the Regional Government and managed by a company selected through a competitive call, and bank credit supported by collaterals guaranteed by Regional Government funds. In 2011, ASTER coordinated various regional business plan competitions to launch the EmiliaRomagna STARTUP, which promoted a network to aggregate regional actors to provide support to new enterprises. It also restructured the Spinner Global Subsidy of 2013, managed by the Spinner Consortium starting in 2000. It provided services and opportunities for young people and aided business creation with research grants that were partly covered by regional companies directly involved in the realization of projects. The Regional Government developed a network of local Spinner points located near universities and research centers, supporting beneficiaries in the presentation of proposals and the development phases of project ideas. The pioneering efforts of the Start Cup competition of the University of Bologna, which had already contributed to the PNICube (see Sect. 3), moved to a new stage. The University began to use the regional level of the competition to ensure the continuity and idea flow needed to keep the competition alive and appealing for investors. ${ }^{13}$

A further step in Regional Government policy followed the introduction of the EU Commission Smart Specialization Strategy (S3). It linked funding dedicated to supporting regional innovation systems to the identification of areas of specialization. EmiliaRomagna engaged different institutions and actors to define its priority areas, ASTER coordinated consultations that involved all members of the Regional High Technology Network.

Although the S3 strategy was more general in its targets and more focused on the role of private companies, it assigned a primary role to the High Technology Network, as well as to universities and PRIs. In 2015, the Regional Government signed a 3-year framework agreement with the universities and PRIs in the regional territory to renew their commitments to the Regional High Technology Network. Their main goal was to strengthen its regional innovation using strategic research projects with a robust industrial purpose. It continued to support Labs and Centers through dedicated calls for proposals. However, it also promoted seven Clusters, - one for each area of the S3-composed of public and private subjects participating in the High Technology Network. These associations aimed to stimulate dialogue among members to collectively define the main technological priorities to innovate and modernize a sector (or system), because of possible regional tenders. They also aimed to identify directions for future research and information needs to favor the modernization of the production system, identify partners in other regions or countries, and suggest regulatory interventions to the Regional Government to facilitate innovative processes. Universities continue to participate in these associations through their interdepartmental research centers.

This last set of policies was deployed through a different approach. The 2003-2007 period focused on how to strengthen the supply and demand for innovative activities by creating new actors (Labs and Centers). The Regional Government acted as a facilitator by using a dedicated budget and a set of competitive calls administered by an Expert Committee, operating in coordination with the government, but with a high degree of autonomy

\footnotetext{
13 The Spinner Consortium was established in 2000 by its founding partners ASTER, Alma Mater Foundation (the University of Bologna's Foundation) and Sviluppo Italia (the national agency for inward investment promotion and enterprise development, now Invitalia) for the implementation of the EU Global Grant within the European Social Fund (ESF) 2000-2006 of Emilia-Romagna Region (https://www.spinner.it/ index.php?pg=170).
} 




No. of patents from Universities in Emilia-Romagna

Source: Patiris

No. of spin-offs from

Universities in

Emilia-Romagna

Source: Spin-off Italia (Netval 2018)

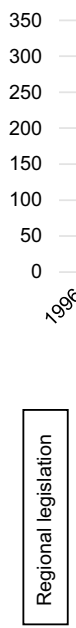

N. of innovative startups in Emilia-Romagna vs. average Italian regions

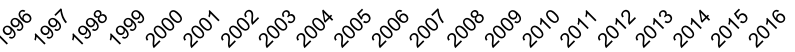

Source: Ministry of Economic Development

E-R Average Italian regions

R.L. 07/2002

First regional law for

supporting and

promoting a regiona

system for industrial

research, innovation

and technology

transfer

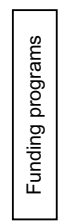

\begin{tabular}{|c|c|}
\hline $\begin{array}{l}\text { PRRIITT 2003- } \\
2005\end{array}$ & $\begin{array}{l}\text { POR FESR 2007- } \\
2013\end{array}$ \\
\hline $\begin{array}{l}\text { - Calls for } \\
\text { industrial }\end{array}$ & 2008 \\
\hline projects & Introduction of the \\
\hline $\begin{array}{l}\text { - Calls for } \\
\text { Research and }\end{array}$ & Tecnopoli program \\
\hline hnology & 2010 \\
\hline osfer & Set up of the High \\
\hline atories & Technology \\
\hline and Innovation & Regional Network \\
\hline
\end{tabular}

2014-2020

Implementation of an

intelligent specialization

strategy S3

- Strengthening of key

industrial sectors

- Enhancement of health

and creative industries

- Fostering of the High

Technology Regional

Network as a referring

point for the

advancement of the

production system

Fig. 3 Knowledge transfer policies and practices at regional level 
and responsibility. The 2007-2013 program focused on the creation of a dedicated regional infrastructure under the direct control of the Regional Government to solve the problem of connecting public research activities and companies. The Regional Government acted as a central planner and pushed for hierarchical control over local universities and PRIs.

In contrast, the 2014-2020 program took for granted the presence of a robust set of actors playing different roles along the innovation process. It acted as a facilitator, investing in a preparatory phase based on public consultation to build consensus. It then retained a light coordination role through specific tenders allocating resources targeted to innovation in a selected set of industries and thematic areas. Figure 3 illustrates the patterns of patents, spin-offs, and innovative start-ups that correspond to various regional institutional efforts implemented over time. In Sect. 5, we turn our attention to the technology transfer policies of the University of Bologna and how they evolved both nationally and regionally.

\section{Knowledge transfer policies and practices at University of Bologna between 1996 and 2016}

The University of Bologna is a multidisciplinary, secular, generalist, public Italian university. With its one-of-a-kind multi-campus organization, and its presence in five provinces of the Emilia-Romagna region, it is one of the largest universities in Italy for number of students, faculty, and staff. ${ }^{14}$ Because of its research and teaching, as well as its history, ${ }^{15}$ it is has a high reputation both nationally and internationally. ${ }^{16}$ Over time, its formal and informal norms and practices have provided significant contributions to the development and enhancement of the Italian university community. Between the late 1990s and early 2000s, as a result of the initiatives of some of its faculty members, it pioneered several initiatives in the area of KTT, setting an example for many other Italian universities (that soon followed suit) (Baldini et al. 2014). Despite these pioneering efforts, however, it did not play a prominent role in the evolution of KTT policies at the national level until 2009, when it joined Netval and became institutionally involved in PNICube. Before that time, it took for granted that all existing initiatives were single projects, pursued by some faculty members; it did not consider the projects to be structural components of its strategic plan. As Sect. 4 notes, the university's priority was to strengthen its fundraising capacity at the EU level. It lacked, however, a specific

\footnotetext{
14 Data on the number of students, teaching staff, and administrative staff of all Italian universities are collected by the Ministry of Education, University and Research and are available at https://www.istruzione.it/ archivio/web/universita/home.html.

15 The University of Bologna was founded in 1088 and is considered one of the oldest universities in the Western world. See https://www.unibo.it/en/university/who-we-are/our-history for more details.

16 For example, the University of Bologna ranks among the first 200 universities in the world according to the 2018 QS World University Ranking. Its reputation among colleagues, stakeholders, and students places it at 69th in the overall ranking (www.topuniversities.com). At the national level, according to the 2018 CENSIS report, it is the largest Italian university (i.e., those with more than 40,000 students) (www.censi s.it).
} 
long-term vision of the relevance of public-private partnerships to move research into practice. $^{17}$

Between 2009 and 2015, Netval and PNICube promoted a new opportunity to participate in various national initiatives, as a result of the proactive attitude of the new Director for Research, who reorganized the activities and the responsibilities strengthening the offices supporting IPR and spin-offs. With the support of its new Managing Director, the University set specific goals to increase licensing revenues and implement a more business-oriented approach to the set-up and management of university spin-offs (University 2009-2012 Strategic Plan). However, it was only almost 20 years after the initial efforts that the University formally incorporated KTT policies into its 2015-2018 strategic plan, with an articulated set of actions and goals, the allocation of dedicated resources, and the full support of its top leadership.

Regulation and management of IPR was the first realm of KTT from which we can trace a formal initiative by the University of Bologna. In 1996, it was the first large generalist university to take advantage of the opportunities provided by changes in national laws on universities, and the first to issue patent regulation (Baldini et al. 2014). Two years later, leveraging on a Master's of Science Thesis in Engineering Management, the University's Director of Research set up the first internal patents database and opened the first IPR office with one dedicated staff member (Informant 2, University of Bologna). Patent applications soon increased, and, over the years, the University of Bologna has placed as one of the top performers in the country. ${ }^{18}$ In the late years of the twentieth century, faculty members led technology transfer initiatives, ${ }^{19}$ mainly through individual contracts with local companies, some of which generated the first university spin-offs.

In 2000, as a result of the contributions of the Bologna Cassa di Risparmio Bank Foundation and the local industry association, the University of Bologna launched its businessplan competition known as Start Cup Bologna. The plan, modeled on the MIT 50K entrepreneurship competition (now known as the MIT 100K Entrepreneurship Competition), was structured in three phases to select the best new business ideas developed by students or faculty. It offered training, mentoring, networking, and dedicated services in collaboration with local chartered public accountants, lawyers, and notary associations. The competition, rising from the commitment of a group of researchers of the Department of Management, aimed to encourage and support technology transfer between the academic world and the market by encouraging academic entrepreneurship. In the first 4 years, over 2000 people participated. ${ }^{20}$ Other universities in the country soon followed suit, leading to the creation of the National Innovation Award and PNICube in 2007 (www.pnicube.it). In 2002, because of this success and the clear demand for services dedicated to university-based

\footnotetext{
17 It is only in the Strategic Plan of 2007-2009 that we find explicit direction for the development of policies and practices for knowledge transfer and strengthening relationships between university research structures and the local business system and institutions (https://www.unibo.it/en/university/who-we-are/strat egic-plan). As Informant 6 explained in an interview, strategic plans at the end of the twentieth century were focused on the construction of new facilities for research and students (e.g., new buildings); since the first years of the twenty-first century, they have focused on the increase of revenues coming from the Sixth and Seventh EU Framework Programmes.

18 See Figs. 1 and 4 that show the trend in the production of patents from 1996 to 2013 (data from the Italian Permanent observatory on universities and PRIs patenting in Italy, Patiris 2018, https://patiris.uibm.gov. it/home).

19 For further details on some of these initiatives, see Serafini (2011) and Romero Munoz (2016).

20 https://magazine.unibo.it/calendario/2005/06/07/startcup2005?d=2005-06-07.
} 
start-ups, the same group of faculty promoted the launch of AlmaCube, the University's Incubator. ${ }^{21}$ In the same period, the Polytechnic of Turin started its own incubator, I3P, and the two universities pioneered the country's development of university-driven incubators, which both contributed to diffuse in the country. I3P, however, grew stronger leveraging on a continued and convinced institutional support (UBI Index 2013, 2014). In contrast, AlmaCube remained a faculty led KTT initiative and was not included in the University's development efforts until its 2009-2012 strategic plan.

In 2000, the new Rector appointed an electronic engineering professor as the new delegate for technology transfer. He was given the mandate to focus on spin-offs and actions to strengthen the IPR bases. The following year, the first Spin-off Regulation was approved, setting the rules for how to establish spin-offs, how faculty and staff could participate in their activities, and how they could use the University's facilities. ${ }^{22}$ Start Cup and AlmaCube were still run in a rather independent way, thanks to the commitment of dedicated faculty members. KTT activities developed mostly through the work of the newly established Spin-off Committee, which focused on a parallel faculty-led set of initiatives rarely scrutinized by the demanding selection process developed by the business-plan competition. Over time, a mix of internal power struggles and lack of long-term vision limited full deployment of many positive initiatives that sprouted during this creative time. ${ }^{23}$ Although many other institutions in the country were looking at these examples and learning from their development to structure their own strategies, they were taken for granted internally. The initiatives that had emerged so spontaneously and rather independently of each other evolved without any special central effort in their coordination or long-term planning. The University's formal actions, however, did not make any significant progress.

Though the support and development of KTT activities lacked a structured plan, the 2003-2005 Regional Government plan promoted the development of industrial research labs (see Sect. 4). University authorities did not formulate a response to the government's calls targeting local universities and PRIs. Thus, professors or groups of faculty members formed initiatives independently. As result, at the end of the selection process, several new Labs were set up, spanning activities that ranged from restoration technologies to life sciences. The Labs clearly represented a relevant part of the newly born Regional High Technology Network. They accounted for one-third of the total new capacity installed and operating in five different technological areas located in six cities (Bologna, Forlì, Cesena, Faenza, Ravenna and Rimini). ${ }^{24}$ Their relevance, however, did not emerge clearly as they were treated internally as any other research grant. Aside from these new Labs,

21 As stated within the Consortium Contract (modified in 2007), AlmaCube was founded in front of the Notary on October 31st 2000, but did not start operations until the spring of 2001.

22 The first Spin-off Regulation was issued with Rector's Decree n.180 on June 6th 2002 (Official Bulletin n.87, 15/06/2002).

${ }^{23}$ It is only with the modification of the Spin-off Regulation (known as "strategic guidelines and operational policy on the subject of promotion of new entrepreneurship and spin-offs in the Alma Mater Studiorum-University of Bologna"), issued in November 2013, that AlmaCube was formally introduced as "the legal entity and the reference structure...both for the design, implementation and management of initiatives to support new entrepreneurship, both for managing the university's role within [university] start-ups and spin-offs ..." (p. 4).

24 Authors' elaboration on data from "Report: Implementation of the first Regional Program for Industrial Research, Innovation and Technology Transfer PRITT 2004-2005". 
however, universities did not create any specific policy for strengthening university-industry collaboration. ${ }^{25}$

During the 2007-2013 period, the absence of University policy on KTT resulted in a power struggle between the group of researchers engaged in the Labs and the University's administration. The former wanted to secure funding for their research activities, while the latter was worried about becoming too dependent on local resources and wanted to avoid any form of external political influence on its research activities:

Several professors already had relations with the Region...about research projects that the Region had launched, but also through other consultancy activities, or participation in commissions. And then they saw in the Region an important development engine in this area. And therefore, they were very keen on the realization of this idea, in short. The concern inside [the University leadership]....I remember that sometimes, reflecting and speaking, [the new Director of the Research Area] was afraid that the main interest of the research in [the university] was going to move [away] from the fundamental, basic, free research, which was the one that was going to compete, for example, in European calls for proposals. (Informant 5, University of Bologna)

In the meantime, however, no other policies could compensate for the lack of internal direction and the proactivity of the Regional Government. At the national level, as discussed in Sect. 3, no structured plans or initiatives were fostering university-industry collaborations. At the continental level, the EU VI Framework Program was issuing competitive calls for financing specific research projects with no specific approach to university-industry collaboration, given the limitations associated with the distribution of policy-making prerogatives between the European Commission and member states. On the one hand, research groups started calling for a softer approach to the Regional Government, downplaying the implications linked to forgoing some of their academic freedom in exchange for additional funding. On the other hand, the Rector took a tough, confrontational stance against any form of direct or indirect control resulting from the new wave of regional financing:

[The Rector] felt he was a bit....I would not say divested...but he posed a problem....

He said: The Region challenges university autonomy....Maybe within certain limits...there could have been...there were some areas of...conflict, let's say....He felt a little that he was put...under pressure by the Regional [Government's] push. (Informant 8, Emilia-Romagna Regional Government)

The discussion, however, focused not on different forms of university-industry collaboration, but its governance and the separation of roles and prerogatives between universities and the Regional Government. The University of Bologna's relevance to the regional economy and its institutional visibility was clear enough to call for a revision of the initial plan-which would have quickly proved ineffective. Some faculty members were able to convince the Rector that the University needed to reconcile different instances. It had both to develop a different vision (compatible with the fundamental values of university

\footnotetext{
25 As previously noted, it is only with the Strategic Plan 2007-2009 that the University of Bologna introduced the strengthening of relationships between university research structures and the local business system and institutions as part of its research agenda.
} 
autonomy and self-governance) to participate in the High Technology Regional Network and to strengthen its effectiveness in interacting with the local economy to enhance technology transfer (Informant 5, University of Bologna).

Accordingly, the university established a specific Tecnopoli Committee, combining faculty who were directly involved in the deployment of the previous regional plan, the University's Research Committee, representatives from the Departments' Chairs Council, and the University's Director of Research (Report from the Tecnopoli Committee, Bologna December 17, 2008). Its mandate was to combine existing Labs with new ideas coming from other research groups and develop an organizational and governance structure. It had to be compatible with the Regional Government constraints and the University's need to retain full control of personnel and infrastructures. The Committee had a three-fold role. First, it needed to talk to all faculty members to ensure this new call was an opportunity to stimulate further engagement leveraging the best technologies and research capacities rather than merely consolidating previously funded groups. Second, it needed an administrative solution that balanced contrasting views on the future governance structure. Third, it needed to interact with the Regional Government, both to secure the technical feasibility of any possible alternative and to recover inter-institutional dialogue to allow all parties to save face.

It, therefore, developed the CIRI concept (see Sect. 4). The centers started as new university units controlled by at least two founding departments, each contributing dedicated research infrastructures, and personnel, complemented by Regional Government funds. They were tasked with increasing interaction with local companies to improve KTT activities. They could not receive any other form of funding from the university, nor could they compete with departments for national or EU funding to avoid unproductive internal competition. After the regionally funded start-up period, CIRIs would become self-sufficient by selling high-value-added technical services to private companies. The various groups clustered in nine such centers, and on December 9, 2009, the Regional Government and University of Bologna signed a bilateral agreement. Their operations started in 2010:

There was a palpable irritation [in the relations between the university and the Regional Government]. So much so that the University of Bologna was the last to sign the agreement with the [Regional Government]....[It signed] right at the last moment. (Informant 4, University of Bologna)

Between that date and 2015, under a newly elected Rector-with a 6-year term, following the national reform of universities introduced in 2010 - the University appointed a Vice-Chancellor for Research and hired a General Manager and a Director for Research. The Vice-Chancellor for Research held several patents and had contributed to founding a 


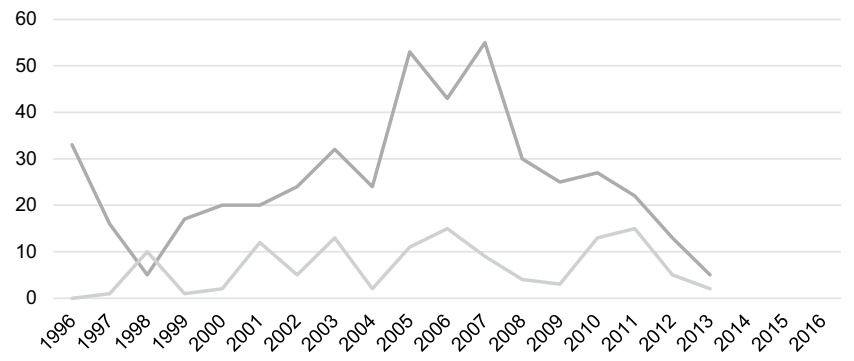

No. of patents University of Bologna vs average Universities in

Emilia-Romagna

Source: Patiris, 2018



No. of spin-offs University of Bologna vs. average

Universities in

Emilia-Romagna

Source: Spin-off Italia (Netval 2018)

Av. Uni ER Unibo

$$
\begin{aligned}
& 1996 \\
& \text { First } \\
& \text { patent } \\
& \text { regulation }
\end{aligned}
$$

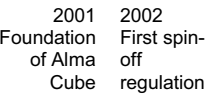

1998-1999

First public

engagement

2000

First edition

of the

business

plan

competition

Start Cup

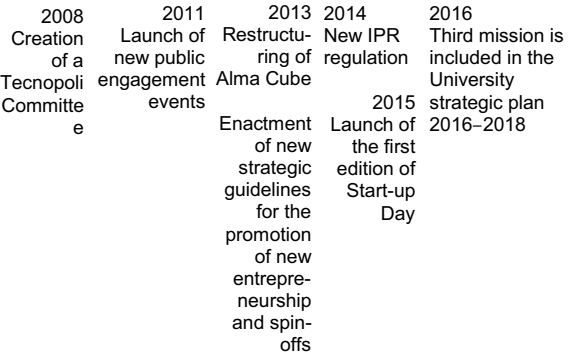

2013-2015

Foundation of

new start-up

incubators in

Cesena and

Forlì

Campuses

Fig. 4 Knowledge transfer policies and practices at University level 
high-tech service company in drug development. The Managing Director had been very active in his previous positions in the Science Park communities and had been Vice-President of their international association for several years. The Research Director, in his previous appointment at the Polytechnic of Milan, had developed its KTO and was one of the Netval's founders. Although the University did not develop any strategy for KTT during those years, this combination of experience and expertise generated a top-down wave of unstructured initiatives, as had occurred 10 years earlier.

In March 2013, AlmaCube became a not-for-profit limited liability company, and the local industrial association joined as a partner. It was Italy's first experience of a university and an industry association forming a company to speed up the incubation processes of business projects born in academic research.

The Spin-Off Regulation and Patent Regulations and Research Evaluation Committee changed to comply with the new provisions introduced by the 2010 reform. In November 2013, new spin-off regulations differentiated the University's support services (i.e., within the KTO and AlmaCube) according to various targets within the university community: start-ups (i.e., new, innovative companies launched by university students and graduates) and spin-offs (i.e., new businesses based on technologies developed by faculty and university research staff). Despite this distinction, however, the regulations focused on university spin-offs by assessing the University's requirements for their accreditation and the University's possible involvement as a shareholder through AlmaCube. The regulations also recognized the importance of coordinating with other regional bodies such as ASTER. ${ }^{26}$ In 2014, the University issued a new IPR Regulation, ${ }^{27}$ finally incorporating the changes introduced at the national level in 2005, as well as a new version of the guidelines for the evaluation of the university research, ${ }^{28}$ and a new Research Evaluation Committee began to operate.

During this period, the University launched three more initiatives to support innovation and entrepreneurship. In 2013, it established CesenaLab within the University's campus in the city of Cesena, according to input from the local Municipality and a local bank foundation. CesenaLab was an incubator focusing on the digital world, web, and new media; and offered free, high-level services (https://www.serinar.unibo.it/cesenalab/). Two years later, in 2015, it initiated a similar experience in Forlì; it was known as the Basement Club and located within the School of Economics, Management, and Statistics at the Forlì Campus (https://site.unibo.it/basementclub/it). In the same year, in Bologna, the University organized the first edition of Startup Day, an event to foster student start-ups by encouraging students with entrepreneurial ideas to connect with other students that had relevant skills and competencies (https://site.unibo.it/startupdayunibo/en/what-how-why/past-editions). As in the late 1990s, all these initiatives began as bottom-up, faculty-led activities; they were not part of a specific development plan endorsed by the University leadership.In 2015, with the election of a new Rector, the University of Bologna gave strong support to KTT and entrepreneurship policies. First, it nominated a Deputy Rector dedicated to entrepreneurship and fostering

\footnotetext{
26 The new strategic guidelines and operational policy about promotion of new entrepreneurship and spinoffs in the Alma Mater Studiorum-University of Bologna were issued in November 2013.

27 The new Regulation on industrial and intellectual property of the University of Bologna became effective April 2014 and was updated in March 2018 (Rector's Decree N. 269 of April 15 2014) (Official Bulletin No. 212 of April 15 2014).

${ }^{28}$ Guidelines for the assessment of the university research were approved by the Board of Directors on March 25th 2014 and were updated on February 24th 2015.
} 
relations with companies. ${ }^{29}$ Second, it gave third mission activities a specific role in the 2016-2018 Strategic Plan. ${ }^{30}$ Third, it reformed its central administration offices to support a new organizational structure dedicated to the third mission (Informants 1 and 2, University of Bologna). It identified two key targets: student entrepreneurship and university-industry collaboration. The organization converted into three offices: spin-off and start-up companies, protection of IPR, and IPR development. Furthermore, it created an office dedicated to company relationships, to promote the University's opportunities with companies. The overall goal was to provide the necessary background to offer a full set of alternatives when engaging with companies, using the experience developed over the years and the excellent reputation of the University. AlmaCube reorganized into three business units: one dedicated to research spin-offs, another as an incubator for student start-ups, and a third (pilot) unit for corporate acceleration selling services to companies (Informant 3, AlmaCube).

Working on student entrepreneurship required renewed effort. Since the first Start Cup competition, the focus had transitioned to faculty-based initiatives. The University's regulations were focused mainly on the accreditation of spin-offs, paying no attention to the conditions for the accreditation of start-ups, and student entrepreneurship was an unmapped phenomenon. ${ }^{31}$ The plan identified four pillars to support student led start-ups, combining a top-down vision with various opportunities to promote bottom up initiatives. ${ }^{32}$ Figure 4 depicts the trends linked to patents and spin-offs from the University of Bologna, alongside the formal and informal initiatives enacted within the University.

\section{Discussion}

The development of events and choices shares several relevant regularities at the three different levels of analysis examined. These regularities are theoretically challenging as well as stimulating for the applied work of decision-makers in the different roles examined. First, norms and practices bounce between formal and informal codification. Although most studies on KTT instruments and practices focus on outcomes and take for granted the processes that led institutions to choose some instruments over others, at all levels of analysis, these processes emerge as key to fully understanding the opportunities and limits for the actors involved. Second, the structural definition of roles falls short of encapsulating the changes in policies and attitudes toward knowledge transfer activities-it must be complemented by an analysis of the relationships among actors at different levels. Treating regional systems as a combination of separate actors balancing multiple internal and external constraints, may not fully represent the challenges of developing innovation policies, as

\footnotetext{
${ }^{29}$ https://magazine.unibo.it/archivio/2015/11/02/il-rettore-francesco-ubertini-presenta-la-squadra-di-gover no.

30 In the Strategic Plan, 2016-2018, the third mission explicitly became one of the three strategic dimensions of the University's policy (together with research and education).

31 As noted, the new strategic guidelines and operational policy about promotion of new entrepreneurship and spin-offs in the University of Bologna, issued in November 2013, acknowledged the existence of student start-ups but did not provide a regulatory framework for this kind of organization.

32 The first experiment with providing students enrolled in all campuses with transversal-competencies training was carried out in the second semester of A.Y. 2016-2017 (https://almaorienta.unibo.it/studentiiscritti/competenze-trasversali-avvio-della-sperimentazione-per-gli-studenti-regolarmente-iscritti-in-corso -nella.a.-2016-2017). In the following academic years, it became part of the formal educational of the University of Bologna https://www.unibo.it/en/teaching/Transversal-competencies-and-other-learning-oppor tunities/transversal-competencies.
} 
it ignores relational dynamics. Third, actor-specific institutional logics evolve and change over time. It is, therefore, essential to recognize the ambiguities generated by misalignment of actors' values, norms, practices, and goals. Moreover, it is misleading to underscore how relevant is their evolution over time and how this evolution depends on how the communities of reference change or exogenous shocks occur. We will discuss evidence related to the three perspectives and present indications for theory and practice.

\subsection{Formal and informal emergence of norms and practices}

KTT policy models assign a central role to normative approaches towards policy definition. National innovation systems rely on the definition of the best fit between resource endowments and levels and types of output expectations. Changes in the nature and characteristics of the resource endowments trigger changes in the systems. However, bottom-up processes and their interaction with top-down norm-based decision making attract limited attention (Goldfarb and Henrekson 2003; Fini et al. 2017). As documented for the Bayh-Dole Act (Owen-Smith 2003; Mowery et al. 2004), however, this might lead to underscore a significant set of explanatory factors. The Act did not directly trigger University patenting but accelerated a trend that had started for some time and responded to the lobbying of different institutions long involved in KTT. Although it changed the institutional landscape, like any significant governmental normative action, the role of informal interactions in the communities of practice played an even more critical role. In that case, the Association of University Technology Managers acted in a way analogous to the one played by Netval in Italy.

Similarly, although with more considerable attention to interactions among various institutions, Triple Helix models hierarchically envision particular stages of development. Models I and II are both considered less effective than Model III (Leydesdorff and Etzkowitz 1996), and treated as previous stages of development. However, moving between models depends on the specificities of local institutional conditions and the relationships among the actors involved. In both approaches, an implicit structure-conduct-performance interpretation of actions and results dominates and has been used widely to model and interpret national and regional systems around the world (e.g., Cooke 2001; Lundvall 1992).

The national-, regional- and even university-level dynamics explored in this paper, add a layer to the complex interaction between formal and informal processes. National and regional laws were introduced more reactively than proactively, on several occasions underestimating the targets' level of development. The definition of IPR rules at the national level took place when universities had already started to work systematically on how to protect their research results. The switch from a university-owned to a professor-privilege regime occurred after internal norms and practices in academia had already started to change (Balconi et al. 2004). The attention to spin-offs from research labs emerged when the phenomenon had already grown significantly in numbers and relevance, stimulating the introduction of special legislation for start-ups rather than the other way around.

Similarly, at the regional level, the development of local networks among public and private actors was highly embedded in pre-existing relational structures. Whenever formal actions enacted by the Regional authority were consistent with this structure, they were accommodated and adopted. Whenever a top-down approach prevailed, relational dynamics dominated over hierarchical structures, and bottom-up informal reactions emerged, forcing policy restructuring and adaptation. 
Even within the University of Bologna, the University did not call for awareness and engagement in KTT activities. If we consider the University's influence at both the national and regional levels, at first glance, we would assume that its formal strategies were instrumental in driving several structural changes. We would conclude that they emerged as the result of forward-looking leadership, steering an institution highly embedded in international networks and able to anticipate change (Baldini et al. 2014). However, closer analysis reveals that all KTT activities emerged from the pioneering efforts of faculty-driven initiatives, rather than from strategic decisions at the university level. Only later in the process were these initiatives considered relevant and structured through internal regulations, practices, and actions.

A formal, reactive response at all levels complemented the proactive, bottom-up initiative and institutionalized attention to the knowledge transfer processes. While an insufficient level of resource endowment or poor structuring of institutional conditions might undermine the effectiveness of top-down policies, an enthusiastic and motivated bottom-up approach might also lack the normative legitimation needed for strengthening and scaling up (DiMaggio and Powell 1983).

In all systems examined in this paper, the current relevance attributed to KTT activities, practices, and impacts is not only stronger, but also more legitimate at all levels than it was in the 1990s, as a result of formal and informal dynamics and their coexistence over time. Tolerance and openness at the University allowed new ideas and approaches to emerge. ${ }^{33}$ The institutional relevance and reputation of the University, both locally and nationally, generated a community of colleagues and a collective impact of otherwise fragmented activities. Taken together, they generated attention to the proper alignment of rules and incentives related to new paradigms and spurred a co-evolutionary process that offers several relevant insights. First, rules are stickier, and change can occur at a faster pace at both organizational and institutional levels, even if new initiatives are merely tolerated rather than supported. Second, change opportunities are more easily detected at the frontier of knowledge than at the governance level. Universities are potent reservoirs of opportunities insofar as their internal organizations and societal roles accept and reward working at the frontier. Their forward-looking roles may generate tensions, depending upon policymakers and regulators' reaction to KTT moving new knowledge from the lab to the field, as with the recent commercial applications of genetics (Gotweiss 1998) and artificial intelligence (Barfield and Pagallo 2018). Third, although local embeddedness and interactions are relevant on many grounds, any functional specializations that they might stimulate could severely limit acting at the frontier. Universities need to strike a balance between the international competition in science, and the greater relevance of localized KTT activities. Local policies need to find appropriate solutions to use their research institutions as bridges to more significant and more challenging communities, especially in less developed regions (Brown 2016; Bonaccorsi 2017).

\subsection{A relational analysis of inter-institutional relationships}

A critical complement of the relevance of the interplay between formal and informal actions is the switch from a structure-conduct-performance perspective to a relational one. Neo-institutionalists showed that organizations compete not just for resources and

33 For a similar observation on the legacy of MIT's KTT activities, see Roberts (2018). 
customers, but also political power and legitimacy (Meyer and Rowan 1977; DiMaggio and Powell 1983), primarily when they use ambiguous technologies to produce outputs that are difficult to appraise (Merton 1973). Efficiency, therefore, cannot be used as a basis for evaluation. The way actors relate to one another and develop a shared understanding of the environment and its challenges become critical to frame the output observed adequately, and power struggles among the actors a critical element to observe.

The problematic interactions between the national legislator and the whole University community at the beginning of this century in Italy experienced on the distribution of IPR rights between the researcher and its institution, shares many similarities with the tense relationship arisen between the Regional Government and the University of Bologna at the time of the second phase of the regional innovation program. These games of policy and practices occurred within the University, undermining many different faculty-driven initiatives that became part of the University's strategic plan only years after their enactment.

At the national level, the bottom-up reaction to an unfavorable change in the national legislation (the so-called professors' privilege) was the formation of an organization promoted by the Universities. Netval thus focused on establishing best practices and reinforcing the collective interest in technology transfer around the country. It acted as a professionalized way to generate isomorphism. It significantly contributed to diffuse a "work-to-rule" approach to the changes in the distribution of IPRs between the University and its faculty. The collective response canceled the effect of the new law in practice. However, it increased the administrative burden experienced by TTOs and introduced a high level of uncertainty when interacting with private companies. The subsequent changes in the legislation might appear driven by an isomorphic adherence to widely accepted international standards (Baldini et al. 2014) but were instead totally dependent on internal political dynamics.

On the one hand, at a formal level, Universities were focusing their attention on the decreasing of national funding, and their interactions with the national Government were all targeting the need to protect their budget, strongly determined by public financing. On the other hand, at an informal level and mainly through Netval, Universities lobbied to eliminate the professors' privilege, accepting a compromise that would not have altered the formal level of negotiation. Although switching from professors' privilege to institutional ownership could have solved the problem, it would have meant loss of face for the national Government. It would have been too costly and would have affected the overall relationship between the Government and the universities. Instead, a particular interpretation of the IPR code law quietly offered a more acceptable compromise and was approved without any significant evidence of the identities of the winners and losers.

At the regional level, the Regional Government's attempt to control part of the universities' resources by introducing a new set of institutional arrangements, generated strong opposition from the University of Bologna. However, together with a formal opposition, we observe the creation of an internal process focused on finding an alternative solution. As previously observed at the national level, while one of the two elements ultimately prevailed and while the presence of an institutional contrast was clear and well known, the solution was formally masquerading those power struggles. New institutions, in the form of new organizational structures within the University of Bologna, emerged as a result of this process (Tracey et al. 2011). We cannot fully account for their role and relevance in the changes produced within the local economy without a proper analysis of the university context.

Although no explicit opposition emerged within the university in the period we examined, organizational power struggles took several different forms. As previously discussed, 
formal and informal processes remained separated for a long period of time, with practitioners of the latter forced to find resources outside the university budget. Moreover, the absence of internal formal legitimization, such as incorporation within the university rules and regulations, kept the University's attention on research-to the detriment of KTT activities. Individual initiatives dominated, generating different forms of interactions among faculty members and local industrial communities; this individualization failed to generate any direct returns to the University, and it misaligned institutional and individual goals and rewards. This misalignment eventually slowed the development of KTT activities in comparison to universities that started later but were more consistent in their approach.

An institutional view of the role of Universities adds significant interpretative elements and is instrumental in unveiling how institutional arrangements emerge (Owen-Smith 2003; Fini and Lacetera 2010). It is a natural companion of the contrast of formal and informal actions by revealing how actors engage in negotiated interactions to align their strategic intent. While all could be driven by a specific rationally determined preference set, even in the presence of a clear hierarchical structure identifying roles and prerogatives, the legitimation of Universities gives them a differentiated set of tools through which they can influence the debate and the resulting environment. Reputation and its leverage options, however, are not a given and will not necessarily last forever, nor are they independent from other structural properties. As we have seen in this paper, the University size mattered in the regional negotiations. At the national level, the reputation of the most relevant universities in the country helped to generate mimetic behavior. It pulled the whole community to join forces, making a collective effort more effective than a selected league one. Many of the currently available analyses focus on the role of Universities looking at different indicators of their impact on societies based on measurable outputs (Bonaccorsi 2017). A full assessment of their function and importance, however, needs to account for the processes behind those outputs and their role, if any, in shaping society as political institutions embedded in different relational sets.

\subsection{Different forms of institutional logics and their evolution}

Activities in the realm of KTT require attitudes, processes, and approaches not aligned with teaching and research — the traditional missions of universities - and are typical of the emergence of multiple institutional logics (Feldman and Desrochers 2004; Fini and Lacetera 2010; Sauermann and Stephan 2013). According to the institutional logics perspective (Thornton and Ocasio 2008; Thornton et al. 2012), individual and organizational actors are influenced by their embeddedness in multiple social locations in inter-institutional systems. Each order of inter-institutional systems distinguishes different organizing principles, practices, and symbols. It is through these principles, practices, and symbols that each institutional order shapes how reasoning takes place. Both individual actors and organizations must reconcile possible conflicting logics in their decisions and actions.

Our analysis highlights different types of institutional logics and describes how they develop over time. Although they are internally coherent when analyzed within their specific boundaries, differences emerge whenever their encounters are not designed or foreseen as relevant aspects to address. In our context, national government policymakers did not deem it necessary to engage universities and PRIs in the definition of professors' privilege, introduced in 2001. That definition reflected a more liberal approach to economic activity consistent with the overall set of new policies and the center-right coalition. However, it contrasted completely with universities' new attitude toward the commercialization 
of science. Indeed, in 2012, with the introduction of new policies for start-ups, several private and public institutions immediately began to communicate to align interests, expectations, and ideas on how to overcome administrative hurdles. They favored the alignment of different institutional logics via increasing shared awareness of the vital role of start-ups and recognizing the critical role played by universities in creating the proper conditions for their emergence from the science labs.

Tension regarding differing institutional logics was also a recurrent pattern in the regional context. During the period we observed, there were several attempts at reconciliation. As Sect. 4 describes, the first part of the Emilia-Romagna regional government's effort to connect the vibrant SME-based economy to the productive public research system relied on the recognition of a strong separation between these two parts of the local ecosystem. The strategy was to create hybrid structures - the Labs-in which companies and researchers would develop joint projects and attempt to reconcile their differences (Villani et al. 2017). This combination did not require institutions to restructure regular activities, concentrate research efforts within new entities, or limit powers and autonomy.

The 2008 decision to merge several of these structures showed that not all had been able to achieve their initial goals. Whereas the most effective structures had created new market-based opportunities, several others could not perform without public subsidies. This selection process, however, was paired with an attempt to put the hybrid structures under Regional Government control, thereby directly affecting the equilibrium between the various institutional logics. Although the dominance of one institutional logic over another was hard for smaller universities to resist, the University of Bologna had the resources it needed to defend its autonomy, and so it did. Rather than rebalancing its private-public relationship within a renewed, blended structure, it set up CIRIs to shelter its Regional Government influence. This defensive attempt conditioned the evolution of KTT practices within the University and slowed the process of formally opening up to higher levels of interaction with the local industrial community. The internal dominance of investments aimed at strengthening the international research recognition of the university reinforced these processes. It gave them priority in the University's multi-year strategic development plan over different types of KTT.

Various institutional logics coexisted within the University of Bologna, showing the importance of properly defining the relevant community of reference for the different principles, practices, and symbols (Sauermann and Stephan 2013). Faculty nurtured initial efforts in the late 1990s and early 2000s, whereas staff slowly developed the bureaucratic arrangements needed to cope with the evolving legal landscape. A second relevant distinction is between those who worked within the different initiatives (the incubator, the business plan competition, and various public engagement activities) and the University leadership. The former nurtured the success, visibility, and national diffusion of various initiatives. The latter took much longer to include KTT activities among its priorities. They first appeared in the 2009-2012 strategic plan, and only with the 2015-2018 plan, they become a central element of the university's strategy.

The combination of different levels of analysis shows how institutional logics evolve and coexist in different forms over time (Owen-Smith 2003). A common feature at all levels is the aligning of formal and informal solutions to tackle new challenges, which requires the combination of different types of resources and approaches. However, confrontation and struggle between differing logics persists and can lead to suboptimal solutions. The introduction of amendments to professors' privilege in the IPR code instead of the elimination of the law, the introduction of CIRIs as structural hybrids, and the separation of research and KTT, are all clear examples of different levels of compromised solutions 
led by persistent differences in institutional logics. We need a full understanding of the impact of universities in society to complement a functionalist view of their role as engines for growth. We also need a careful specification of the various institutional logics at stake, their evolution, and their relevance in shaping the interaction space.

\section{Conclusions and limitations}

Universities can contribute to society in several ways, but any full understanding of their role must consider their embeddedness in a complex set of relationships. They are simultaneously members of their peer communities, local ecosystems, national institutional spaces, and in some cases, global communities. We presented a historical case study centered on the University of Bologna and its knowledge transfer policies and practices between 1996 and 2016, to model the complex dynamics that connect these different levels. Our findings suggest the importance of adequately mapping multi-level interactions to determine how universities' impact on society develops, not only by directly affecting the economy but also by shaping institutions.

Our study is limited to the observation of one university in one region and one country. It uses archival documents that may not fully represent specific events. We complemented these documents with direct interviews of key informants, whom we asked to recall events that stretched back in time. In addition to memory-retrieval problems, we may not have contacted all relevant actors and therefore collected a biased narrative of events. Moreover, one author was directly involved in many of the national, regional, and university level events that we analyzed (Van Maanen 1988). To overcome these methodological problems, we paid attention to triangulating our sources, challenging document regularities through interviews, and comparing our findings with existing publications (Langley 1999). None of the aspects or events that we analyzed relied solely on our involvement and memory, and not all aspects or events analyzed emerged from our involvement or memory. Although we cannot rule out all possible sources of bias, we believe that our findings are robust and offer several interesting insights.

We chose to focus on the University of Bologna because of its prominence and relevance both for the Emilia-Romagna region, where it operates through its five branches, and for Italy as a whole, where it has a longstanding reputation and has had measurable success. Many other universities in the world, such as Katholeike Universiteit (KU) Leuven in Belgium, Tsinghua in Beijing, National University of Science and Technology (MISiS) in Moscow, and the University of Sao Paulo in Brazil, share similar characteristics. They are enduring institutions that have generated direct outputs in their territories of operations and grown their reputation and influence at the national level. They have also struggled to remain locally relevant and internationally competitive, even when their national resource endowments put them at a disadvantage. Therefore, although we analyze only one Italian institution, we believe that our findings are relevant to understanding the role of prominent universities in general and offer specific insights for scholars, policymakers, and university leaders.

Conceptually, we suggest that universities balance the specificities of their local economic and social environment with convergent pressures in the international competition for talents. Although not all universities are in territories rich with advanced industrial activities, they are all pushed by national policies and global trends to excel in science, teaching, and transferring advanced knowledge to society. They can be 
instrumental in promoting change, but they cannot act alone. Working at the forefront may misalign them with the needs and competencies of other institutions that play complementary and essential roles. Our analysis shows that it took a long time for the University of Bologna's pioneering efforts in knowledge transfer policies and practices to become entirely accepted nationally and locally. It also shows that the entire process depended on a complex mix of formal and informal actions, developed through multiple institutional logics that generated high levels of ambiguity and blended top-down strategies with bottom-up initiatives. Several accounts of the impacts of many prestigious universities seem to suggest there is rationality in pursuing knowledge transfer activities (Breznitz and Etzkowitz 2016). A more detailed and articulated account of decisionmaking processes, their evolution over time, and their fit or misfit with various levels of interaction, however, advances our theoretical knowledge of the role of universities as institutions (Kenney and Mowery 2014).

These findings offer a caveat to policymakers challenged to develop the next Silicon Valley on the outskirts of Moscow, Mumbai, Dubai, Nantes, or any other part of the world. Top-down initiatives to quickly move science from labs to shelves, supported by dedicated funding, and focused on setting up new institutions endowed with more flexibility, are doomed to fail (Lerner 2009). Significant resource asymmetry or lack of reputation could be a tempting set of explanations suggesting additional boosting to the program and heavy reliance on star scientists hiring policies. However, one will continue to miss the target. Universities' impact depends on a delicate mix of formal and informal influence on how their peers consider and value their actions and use them to change or, instead, to resist to change. In highly institutionalized environments such as universities, and especially in countries with longstanding traditions of education and research, newcomers must earn their roles before becoming credible as change agents. It is always tempting to start with greenfield investments to support the local economic environment. However, full recognition of the role of Universities as crucial contributors in policy development suggests to partner with existing ones and promote a mutual adaptation approach that abandons the one-size-fit-all bias too often applied to the definition of local development policies (Brown 2016).

University leadership should also carefully consider these dynamics. Our evidence suggests that any top-down process led by strong leadership must cope with the level of awareness and acceptance of the organizational environment. For scholars of universities as institutions, it should not be surprising that the coexistence of different institutional logics, the long-lasting nature of universities, and the freedom granted to faculty, all point to the need for more engaging leadership styles. This is particularly true for KTT activities competing for attention against teaching and research resources and, even now, may not be considered legitimate. We found evidence of these dynamics within a university that had pioneered KTT activities and practices in Italy and been instrumental in diffusing them both regionally and nationally. Therefore, in less innovative or proactive institutions, those dynamics are even more critical.

Of the various forms of KTT, we focused on patents, spin-offs, and research-industry collaborations. However, universities affect society in many other ways, and they are increasingly more relevant in the scholarly debate (e.g., Mody 2006; Nelson 2012), and concerning more practical applications such as national research assessment exercises (Barker 2007), including in Italy (ANVUR 2015). A more comprehensive analysis of under-examined forms of KTT activities, such as consulting, student internships, and the role of university museums and art collections, could further improve our understanding of the dynamics we examined. Although we moved through different levels 
of analysis, we did not consider the individual level. Future research could take a more individual-level perspective by focusing on faculty, staff, or students and incorporate their roles in shaping their institutions' logic, actions, and impacts. This research could help overcome another limitation of our perspective-that is, we mostly examined formal, structured actions and processes. As studies (e.g., Goel and Göktepe-Hultén 2018) have documented, including within the University of Bologna (Romero Munoz 2016; Serafini 2011), analysis of the informal activities of faculty could offer additional insights in interpreting our results.

Acknowledgements The authors acknowledge financial support from project EU 780960-AIRBorne H2020-ICT-2017-1 call. They thank Anna Guagnini, Matteo Serafini, the editors of this special issue, and the two anonymous reviewers for their help throughout the process. They are particularly grateful to all those who accepted to be interviewed and share their memories and documents used for our research. All interpreations and errors remain our responsibility.

Open Access This article is licensed under a Creative Commons Attribution 4.0 International License, which permits use, sharing, adaptation, distribution and reproduction in any medium or format, as long as you give appropriate credit to the original author(s) and the source, provide a link to the Creative Commons licence, and indicate if changes were made. The images or other third party material in this article are included in the article's Creative Commons licence, unless indicated otherwise in a credit line to the material. If material is not included in the article's Creative Commons licence and your intended use is not permitted by statutory regulation or exceeds the permitted use, you will need to obtain permission directly from the copyright holder. To view a copy of this licence, visit https://creativecommons.org/licenses/by/4.0/.

\section{References}

Abramo, G., \& D'Angelo, C. A. (2015). The VQR, Italy's second national research assessment: Methodological failures and ranking distortions. Journal of the Association for Information Science and Technology, 66, 2202-2214.

Aghion, P., Dewatripont, M., \& Stein, J. (2008). Academic freedom, private sector focus, and the process of innovation. RAND Journal of Economics, 39(3), 617-635.

Anselin, L., Varga, A., \& Acs, Z. (1997). Local geographic spillovers between university research and high technology innovations. Journal of Urban Economics, 42(3), 422-448.

ANVUR. (2015). La valutazione della terza missione delle Università italiane: manuale di valutazione della terza missione. Retrieved May 2018 from https://www.anvur.it/attachments/article/26/Manuale\%20val utazione\%20terza .pdf.

ANVUR. (2018). Rapporto Biennale sullo Stato del Sistema Universitario e della Ricerca 2018. Retrieved May 2018 from https:/www.anvur.it/en/biennial-report/biennial-report-2018/.

Audretsch, D. B. (2014). From the entrepreneurial university to the university for the entrepreneurial society. The Journal of Technology Transfer, 39(3), 313-321.

Audretsch, D. B., Cunningham, J. A., Kuratko, D. F., Lehmann, E. E., \& Menter, M. (2019). Entrepreneurial ecosystems: Economic, technological, and societal impacts. The Journal of Technology Transfer, 44(2), 313-325.

Autio, E., Kenney, M., Mustar, P., Siegel, D., \& Wright, M. (2014). Entrepreneurial innovation: The importance of context. Research Policy, 43(7), 1097-1108.

Balconi, M., Breschi, S., \& Lissoni, F. (2004). Networks of inventors and the role of academia: An exploration of Italian patent data. Research Policy, 33(1), 127-145.

Baldini, N., Fini, R., Grimaldi, R., \& Sobrero, M. (2014). Organisational change and the institutionalisation of university patenting activity in Italy. Minerva, 52(1), 27-53.

Baldini, N., Grimaldi, R., \& Sobrero, M. (2006). Institutional changes and the commercialization of academic knowledge: A study of Italian universities' patenting activities between 1965 and 2002. Research Policy, 35(4), 518-532.

Bansal, P., Smith, W. K., \& Vaara, E. (2018). New ways of seeing through qualitative research. Academy of Management Journal, 61(4), 1189-1195.

Barfield, W., \& Pagallo, U. (Eds.). (2018). Research handbook on the law of artificial intelligence. Cheltenham: Edward Elgar. 
Barker, K. (2007). The UK research assessment exercise: The evolution of a national research evaluation system. Research Evaluation, 16(1), 3-12.

Becattini, G., Bellandi, M., \& De Propris, L. (2009). A handbook of industrial districts. Cheltenham: Edward Elgar.

Belussi, F., Sammarra, A., \& Sedita, S. R. (2010). Learning at the boundaries in an "open regional innovation system": A focus on firms' innovation strategies in the Emilia Romagna life science industry. Research Policy, 39(6), 710-721.

Bergmann, H., Hundt, C., \& Sternberg, R. (2016). What makes student entrepreneurs? On the relevance (and irrelevance) of the university and the regional context for student start-ups. Small Business Economics, 47(1), 53-76.

Bianchi, P., \& Labory, S. (2011). Industrial policy after the crisis: The case of the Emilia-Romagna region in Italy. Policy Studies, 32(4), 429-445.

Bolzani, D., Fini, R., Grimaldi, R., \& Sobrero, M. (2014). University spin-offs and their impact: Longitudinal evidence from Italy. Economia e Politica Industriale, 4, 237-263.

Bonaccorsi, A. (2017). Addressing the disenchantment. Universities and regional development. Journal of Economic Policy Reform, 20(4), 293-320.

Breschi, S., Lissoni, F., \& Montobbio, F. (2008). University patenting and scientific productivity: A quantitative study of Italian academic inventors. European Management Review, 2, 91-109.

Breznitz, S. M., \& Etzkowitz, H. (Eds.). (2016). University technology transfer: The globalization of academic innovation. Abingdon: Routledge.

Brown, R. (2016). Mission impossible? Entrepreneurial universities and peripheral regional innovation systems. Industry and Innovation, 23(2), 189-205.

Cainelli, G., \& Zoboli, R. (Eds.). (2004). The evolution of industrial districts: Changing governance, innovation and internationalisation of local capitalism in Italy. New York, NY: Physyca-Verlag Heidelberg.

Capano, G., Regini, M., \& Turri, M. (2016). Changing governance in universities. Italian higher education in comparative perspective. London: Palgrave MacMillan.

Capano, G., \& Turri, M. (2017). Same governance template but different agencies. Higher Education Policy, 30, 225-243.

Cesaroni, F., \& Piccaluga, A. (2016). The activities of university knowledge transfer offices: Towards the third mission in Italy. The Journal of Technology Transfer, 41(4), 753-777.

Chiesa, V., \& Piccaluga, A. (2000). Exploitation and diffusion of public research: The case of academic spin-off companies in Italy. R\&D Management, 30(4), 329-340.

Colombo, M. G., D’Adda, D., \& Piva, E. (2010). The contribution of university research to the growth of academic start-ups: An empirical analysis. Journal of Technology Transfer, 35(1), 113-140.

Cooke, P. (2001). Regional innovation systems, clusters, and the knowledge economy. Industrial and Corporate Change, 10(4), 945-974.

Dasgupta, P., \& David, P. A. (1994). Toward a new economics of science. Research Policy, 23(5), 487-521.

DiMaggio, P., \& Powell, W. (1983). The iron cage revisited: Institutional isomorphism and collective rationality in organizational fields. American Sociological Review, 48(2), 147-160.

Eesley, C., Yang, D., Roberts, E. B., \& Li, T. (2016). Understanding entrepreneurial process and performance: A cross-national comparison of alumni entrepreneurship between MIT and Tsinghua University. Asian Journal for Innovation and Policy, 5(2), 147-185.

Elton, L. (2000). The UK research assessment exercise: Unintended consequences. Higher Education Quarterly, 54(3), 274-283.

Etzkowitz, H., \& Leydesdorff, L. (2000). The dynamics of innovation: From national systems and "Mode 2" to a triple helix of university-industry-government relations. Research Policy, 29(2), 109-123.

Etzkowitz, H., Webster, A., Gebhardt, C., \& Cantisano Terra, B. R. (2000). The future of the university and the university of the future: Evolution of ivory tower to entrepreneurial paradigm. Research Policy, 2, 313-330.

Feldman, M., \& Desrochers, P. (2003). Research universities and local economic development: Lessons from the history of the Johns Hopkins University. Industry and Innovation, 10(1), 5-24.

Feldman, M. P., \& Desrochers, P. (2004). Truth for its own sake: Academic culture and technology transfer at Johns Hopkins University. Minerva, 42, 105-126.

Feldman, M. P. (1999). The new economics of innovation, spillovers and agglomeration: A review of empirical studies. The Economics of Innovation and New Technology, 8, 5-25.

Fini, R., Fu, K., Mathisen, M., Rasmussen, E., \& Wright, M. (2017). Institutional determinants of university spin-off quantity and quality: A longitudinal, multi-level, cross-country study. Small Business Economics, 48(2), 361-391. 
Fini, R., Grimaldi, R., Santoni, S., \& Sobrero, M. (2011). Complements or substitutes? The role of universities and local context in supporting the creation of academic spin-offs. Research Policy, 40(8), 1113-1127.

Fini, R., \& Lacetera, N. (2010). Different yokes for different folks: Individual preferences, institutional logics, and the commercialization of academic research. In G. D. Libecap, M. Thursby, \& S. Hoskinson (Eds.), Spanning boundaries and disciplines: University technology commercialization in the idea age (Advances in the study of entrepreneurship, innovation and economic growth) (Vol. 21, pp. 1-25). Bingley: Emerald Group Publishing.

Foray, D., \& Lissoni, F. (2010). University research and public-private interaction. In N. Rosenberg \& B. Hall (Eds.), Handbook of economics of technical change (pp. 275-314). North Holland: Elsevier.

Goel, R. K., \& Göktepe-Hultén, D. (2018). What drives academic patentees to bypass TTOs? Evidence from a large public research organisation. The Journal of Technology Transfer, 43(1), 240-258.

Goldfarb, B., \& Henrekson, M. (2003). Bottom-up versus top-down policies towards the commercialization of university intellectual property. Research Policy, 32(4), 639-658.

Gotweiss, H. (1998). Governing molecules: The discursive politics of genetic engineering in Europe and the United States. Cambridge, MA: MIT Press.

Grimaldi, R., Kenney, M., Siegel, D. S., \& Wright, M. (2011). 30 years after Bayh-Dole: Reassessing academic entrepreneurship. Research Policy, 40(8), 1045-1057.

Guiso, L., Sapienza, P., \& Zingales, L. (2004). Does local financial development matter? The Quarterly Journal of Economics, 119, 929-969.

Humphrey, J., \& Schmitz, H. (1998). Trust and inter-firm relations in developing and transition economies. The Journal of Development Studies, 34(4), 32-61.

Kenney, M., \& Mowery, D. C. (Eds.). (2014). Public universities and regional growth: Insights from the University of California. Stanford: Stanford University Press.

Langley, A. (1999). Strategies for theorizing from process data. Academy of Management Review, 24(4), $691-710$.

Lerner, J. (2009). Boulevard of broken dreams: Why public efforts to boost entrepreneurship and venture capital have failed-And what to do about it. Princeton: Princeton University Press.

Leydesdorff, L., \& Etzkowitz, H. (1996). Emergence of a triple helix of university-industry-government relations. Science and Public Policy, 23(5), 279-286.

Link, A. N., Siegel, D. S., \& Bozeman, B. (2007). An empirical analysis of the propensity of academics to engage in informal university technology transfer. Industrial and Corporate Change, 16, 641-655.

Lissoni, F. (2012). Academic patenting in Europe: An overview of recent research and new perspectives. World Patent Information, 34(3), 197-205.

Lissoni, F., Pezzoni, M., Potì, B., \& Romagnosi, S. (2013). University autonomy, the professor privilege and academic patenting: Italy, 1996-2007. Industry and Innovation, 20(5), 399-421.

Lundvall, B.-A. (Ed.). (1992). National innovation systems: Towards a theory of innovation and interactive learning. London: Pinter.

Merton, R. K. (1973). The sociology of science: Theoretical and empirical investigations. Chicago: Chicago University Press.

Meyer, J. W., \& Rowan, B. (1977). Institutionalized organizations: Formal structure as myth and ceremony. American Journal of Sociology, 83(2), 340-363.

MIUR Portale dei Dati dell'Istruzione Superiore. Retrieved May 2018 from https://ustat.miur.it.

Mody, C. C. (2006). Corporations, universities, and instrumental communities: Commercializing probe microscopy, 1981-1996. Technology and Culture, 47(1), 56-80.

Morosini, P. (2004). Industrial clusters, knowledge integration and performance. World Development, 32(2), 305-326.

Mowery, D. C., Nelson, R. R., Sampat, B. N., \& Ziedonis, A. A. (2004). Ivory tower and industrial innovation: University-industry technology transfer before and after the Bayh-Dole Act. Stanford, CA: Stanford University Press.

Nelson, A. J. (2012). Putting university research in context: Assessing alternative measures of production and diffusion at Stanford. Research Policy, 41(4), 678-691.

Nelson, R. R. (Ed.). (1993). National innovation systems: A comparative analysis. Oxford: Oxford University Press.

Owen-Smith, J. (2003). From separate systems to a hybrid order: Accumulative advantage across public and private science at research one universities. Research Policy, 32(6), 1081-1104.

Paletta, A. (2004). Il governo dell'Università tra competizione ed accountability. Bologna: Il Mulino. 
Perkmann, M., McKelvey, M., \& Phillips, N. (2019). Protecting scientists from Gordon Gekko: How organizations use hybrid spaces to engage with multiple institutional logics. Organization Science, 30(2), 298-318.

Piore, M. J., \& Sabel, C. F. (1984). The second industrial divide: Possibilities for prosperity. New York: Basic Books.

Polifroni, M. (2016). Valori e principi di fondo dell'istituzione universitaria. In C. Mio (Ed.), La rendicontazione sociale negli Atenei italiani: valori, modelli, misurazioni (pp. 25-39). Milano: Franco Angeli.

Roberts, E. B. (2018). Celebrating entrepreneurship: A half-century of MIT's growth and impact. Cambridge, MA: MIT Press.

Romero Munoz, J. F. (2016). Networks, alliances and social capital in innovation processes: The cases of biotechnology from Puebla and Bologna. University of Bologna, unpublished doctoral dissertation. Retrieved May 25, 2020 from https://amsdottorato.unibo.it/7740.

Sauermann, H., \& Stephan, P. (2013). Conflicting logics? A multidimensional view of industrial and academic science. Organization Science, 24(3), 889-909.

Serafini, M. (2011). Technological innovation in Emilia-Romagna: Knowledge, practice, strategies. University of Bologna, unpublished doctoral dissertation. Retrieved May 25, 2020 from https://amsdo ttorato.unibo.it/3724.

Siegel, D. S., \& Wright, M. (2015). Academic entrepreneurship: Time for a rethink? British Journal of Management, 26(4), 582-595.

The Economist. (2017). Europe's leaden-toed boot. March 25, 36.

Thornton, P. H., \& Ocasio, W. (2008). Institutional logics. In R. Greenwood, C. Oliver, K. Sahlin, \& R. Suddaby (Eds.), The Sage handbook of organizational institutionalism (pp. 99-129). London: Sage.

Thornton, P. H., Ocasio, W., \& Lounsbury, M. (2012). The institutional logics perspective: A new approach to culture, structure, and process. Oxford: Oxford University Press.

Times Higher Education. (2019). World University Ranking. Retrieved May 25, 2020 from https://www. timeshighereducation.com/.

Tracey, P., Phillips, N., \& Jarvis, O. (2011). Bridging institutional entrepreneurship and the creation of new organizational forms: A multilevel model. Organization Science, 22(1), 60-80.

Tseng, A. A., \& Raudensky, M. (2014). Performance evaluations of technology transfer offices of major US research universities. Journal of Technology Management \& Innovation, 9(1), 93-102.

UBI Index. (2013). Top university business incubators global benchmark 2013. Retrieved May 25, 2020 from https://ubi-global.com/product/top-university-business-incubators-global-benchmark-2013.

UBI Index. (2014). Global benchmark 14/15 report at top university business incubators. Retrieved May 25 , 2020 from https://ubi-global.com/product/top-university-business-incubators-global-benchmark-14-15.

Unioncamere Emilia-Romagna. (2018). Rapporto 2018 sull'economia regionale. Retrieved May 25, 2020 from https:/www.ucer.camcom.it/studi-ricerche/analisi/rapporto-economia-regionale/pdf/2015/2018rapporto-economia-regionale.pdf/view.

Valero, A., \& Van Reenen, J. (2019). The economic impact of universities: Evidence from across the globe. Economics of Education Review, 68, 53-67.

Van Looy, B., Landoni, P., Callaert, J., Van Pottelsberghe, B., Sapsalis, E., \& Debackere, K. (2011). Entrepreneurial effectiveness of European universities: An empirical assessment of antecedents and tradeoffs. Research Policy, 40(4), 553-564.

Van Maanen, J. (1988). Tales of the field: On writing ethnographies. Chicago: Chicago University Press.

Villani, E., Greco, L., \& Phillips, N. (2015). Understanding value creation in public-private partnerships: A comparative case study. Journal of Management Studies, 54(6), 876-905.

Villani, E., Rasmussen, E., \& Grimaldi, R. (2017). How intermediary organizations facilitate universityindustry technology transfer: A proximity approach. Technological Forecasting and Social Change, 114(C), 86-102.

Wadhwani, R. D., Galvez Behar, G., Mercelis, G., \& Guagnini, A. (2017). Academic entrepreneurship and institutional change in historical perspective. Management and Organizational History, 12(3), $175-198$.

Yin, R. K. (2003). Case study research (Vol. 5). Thousand Oaks, CA: Sage.

Publisher's Note Springer Nature remains neutral with regard to jurisdictional claims in published maps and institutional affiliations. 